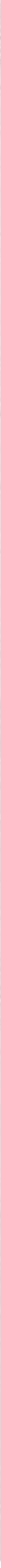




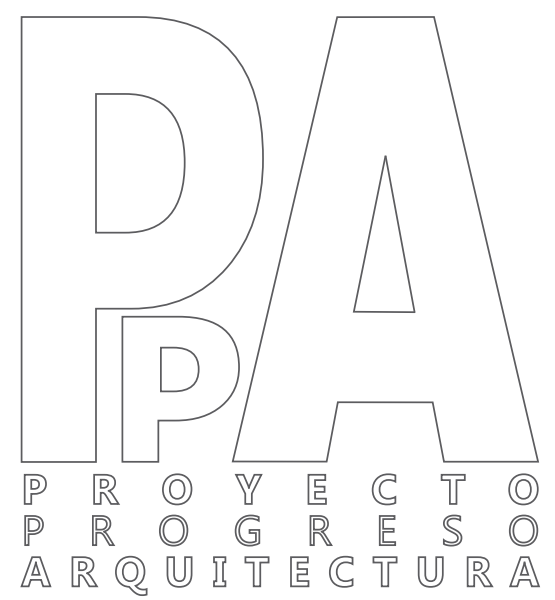

\section{EMERGENCIAS DEL ESPACIO COMÚN}

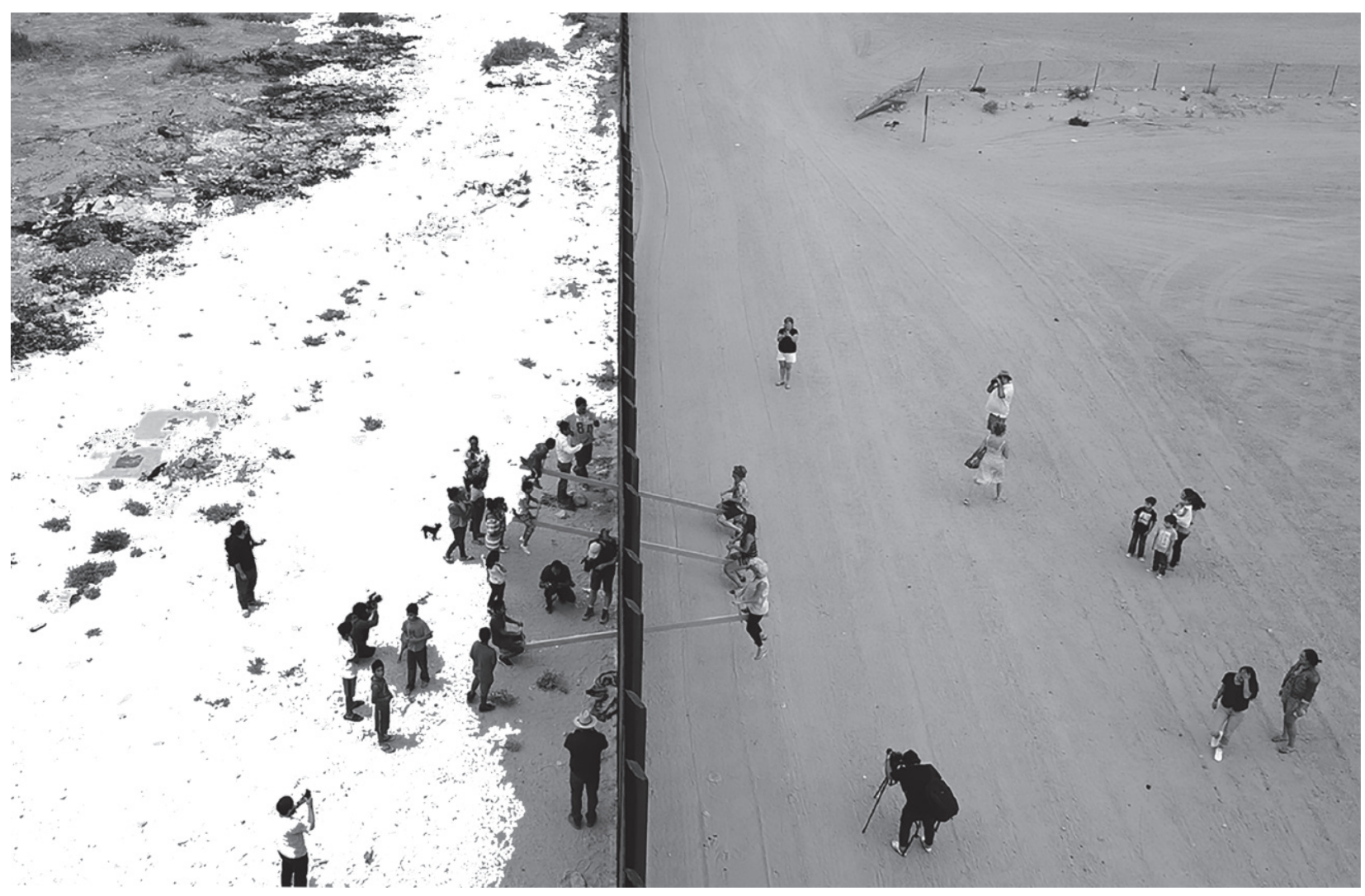

EDITORIAL UNIVERSIDAD DE SEVILLA AÑO 2019. ISSN 2171-6897 ISSNe 2173-1616 DOI: http://dx.doi.org/10.12795/ppa 


\section{REVISTA PROYECTO PROGRESO ARQUITECTURA}

\section{N255}

\section{emergencias del espacio común}
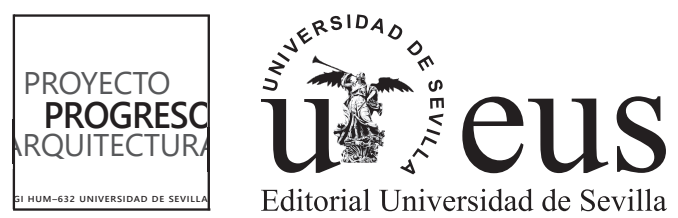


\section{emergencias del espacio común}

EDITA

Editorial Universidad de Sevilla. Sevilla

DIRECCIÓN CORRESPONDENCIA CIENTÍFICA

E.T.S. de Arquitectura. Avda Reina Mercedes, nº $241012-$

Sevilla.

Amadeo Ramos Carranza, Dpto. Proyectos Arquitectónicos.

e-mail: revistappa.direccion@gmail.com

\section{EDICIÓN ON-LINE}

Portal informático https://revistascientificas.us.es/index.php/ppa Portal informático Grupo de Investigación HUM-632

http://www. proyectoprogresoarquitectura.com

Portal informático Editorial Universidad de Sevilla http://www. editorial.us.es/

(c) EDITORIAL UNIVERSIDAD DE SEVILLA, 2019.

Calle Porvenir, 27. 41013 SEVILLA. Tfs. 954487447 / 954487451

Fax 954487443. [eus4@us.es] [http://www.editorial.us.es]

(c) TEXTOS: SUS AUTORES,

(C) IMÁGENES: SUS AUTORES Y/O INSTITUCIONES

DISEÑO PORTADA:

Rosa María Añón Abajas - Amadeo Ramos Carranza

En base a la fotografía: Cortesía y (c) Rael San Fratello, 2019.

DISEÑO PLANTILLA PORTADA-CONTRAPORTADA

Miguel Ángel de la Cova Morillo-Velarde

DISEÑO PLANTILLA MAQUETACIÓN

Maripi Rodríguez

MAQUETACIÓN

Referencias Cruzadas

CORRECCION ORTOTIPOGRÁFICA

Deculturas

ISSN (ed. impresa): 2171-6897

ISSN-e (ed. electrónica): 2173-1616

DOI: http://dx.doi.org/10.12795/ppa

DEPÓSITO LEGAL: SE-2773-2010

PERIOCIDAD DE LA REVISTA: MAYO Y NOVIEMBRE

IMPRIME: PODIPRINT

Reservados todos los derechos. Ni la totalidad ni parte de esta revista puede reproducirse o transmitirse por ningún procedimiento electrónico o mecánico, incluyendo fotocopia, grabación magnética o cualquier almacenamiento de información y sistema de recuperación, sin permiso escrito de la Editorial Universidad de Sevilla.

Las opiniones y los criterios vertidos por los autores en los artículos firmados son responsabilidad exclusiva de los mismos. 


\section{DIRECCIÓN}

Dr. Amadeo Ramos Carranza. Escuela Técnica Superior de Arquitectura. Universidad de Sevilla. España

\section{SECRETARÍA}

Dra. Rosa María Añón Abajas. Escuela Técnica Superior de Arquitectura. Universidad de Sevilla. España

\section{EQUIPO EDITORIAL \\ Edición:}

Dr. Amadeo Ramos Carranza. Escuela Técnica Superior de Arquitectura. Universidad de Sevilla. España.

Dra. Rosa María Añón Abajas. Escuela Técnica Superior de Arquitectura. Universidad de Sevilla. España.

Dr. Francisco Javier Montero Fernández. Escuela Técnica Superior de Arquitectura. Universidad de Sevilla. España.

Dra. Esther Mayoral Campa. Escuela Técnica Superior de Arquitectura. Universidad de Sevilla. España.

Dr. Miguel Ángel de la Cova Morillo-Velarde. Escuela Técnica Superior de Arquitectura. Universidad de Sevilla. España.

Dr. Germán López Mena. Escuela Técnica Superior de Arquitectura. Universidad de Sevilla. España.

Dra. Gloria Rivero Lamela. Escuela Técnica Superior de Arquitectura. Universidad de Sevilla. España.

Juan José López de la Cruz. Escuela Técnica Superior de Arquitectura. Universidad de Sevilla. España.

Guillermo Pavón Torrejón. Escuela Técnica Superior de Arquitectura. Universidad de Sevilla. España.

Externos edición (asesores):

Dr. José Altés Bustelo. Escuela Técnica Superior de Arquitectura. Universidad de Valladolid. España.

Dr. Carlos Arturo Bell Lemus. Facultad de Arquitectura. Universidad del Atlántico. Colombia.

Dr. José de Coca Leicher. Escuela Técnica Superior de Arquitectura. Universidad Politécnica de Madrid. España. Dra. Patricia de Diego Ruiz. Escuela Técnica Supeiror de Arquitectura y Geodesia. Universidad Alcalá de Heranes. España.

Dr. Alfonso del Pozo y Barajas. Escuela Técnica Superior de Arquitectura. Universidad de Sevilla. España.

Dr. Jaume J. Ferrer Fores. Escola Tècnica Superior

d'Arquitectura de Barcelona. Universitat Politècnica de Catalunya. España.

Dra. Laura MArtínez Guereñu. El School of Architecture \& Design, IE University, Madrid; Segovia. España.

Dra. Clara Mejía Vallejo. Escuela Técnica Superior de Arquitectura. Universidad Politécnica de Valencia. España.

Dra. Luz Paz Agras. Escuela Técnica Superior de Arquitectura. Universidade da Coruña. España.

Dra. Marta Sequeira. CIAUD, Faculdade de Arquitectura da Universidade de Lisboa, Portugal.

\section{SECRETARÍA TÉCNICA}

Dra. Gloria Rivero Lamela. Escuela Técnica Superior de Arquitectura. Universidad de Sevilla. España.

\section{EDITOR DEL NÚMERO Y COORDINACIÓN DE LOS CONTENIDOS CIENTÍFICOS}

Dr. Miguel Ángel de la Cova Morillo-Velarde. Escuela Técnica Superior de Arquitectura. Universidad de Sevilla. España.

\section{COMITÉ CIÉNTIFICO}

Dr. Carlo Azteni. DICAAR. Dipartimento di Ingegneria Civile, Ambientale e Architettura. University Of Cagliari. Italia.

Dra. Maristella Casciato. GETTY Research Institute, GETTY, Los Angeles. Estados Unidos.

Dra. Anne Marie Châtelet. École Nationale Supérieure D'Architecture de Strasbourg (ENSAS). Francia.

Dr. Jean Louis Cohen. Institute of Fine Arts, New York University. Estados Unidos.

Dra. Josefina González Cubero. Escuela Técnica Superior de Arquitectura. Universidad de Valladolid. España.

Dr. José Manuel López Peláez. Escuela Técnica Superior de Arquitectura. Universidad Politécnica de Madrid. España.

Dra. Maite Méndez Baiges. Departamento de Historia del Arte. Universidad de Málaga. España.

Dr. Dietrich C. Neumann. Brown University In Providence, Ri (John Nicholas Brown Center For Public Humanities And Cultural Heritage). Estados Unidos.

Dr. Víctor Pérez Escolano. Catedrático Historia, Teoría y Composición Arquitectónicas. Escuela Técnica Superior de Arquitectura. Universidad de Sevilla. España.

Dr. Jorge Torres Cueco. Catedrático Proyectos Arquitectónicos. Escuela Técnica Superior de Arquitectura. Universitat Politècnica de València. España.

Dr. ir. Frank van der Hoeven, TU DELFT. Architecture and the Built Environment, Netherlands

\section{CORRESPONSALES}

Pablo de Sola Montiel. The Berlage Centre for Advanced Studies in Architecture and Urban Design. Paises Bajos.

Dr. Plácido González Martínez. Tongji University Caup (College Of architectura \& Urban Planing). Shangai, China.

Patrícia Marins Farias. Faculdade de Arquitetura. Universidade Federal da Bahia. Brasil.

Dr. Daniel Movilla Vega. Umeå School of Architecture. Umeå University. Suecia.

Dr. Pablo Sendra Fernández. The Bartlett School of Planning. University College London. Inglaterra.

Alba Zarza Arribas. Centro de Estudos Arnaldo Araújo, Porto. Portugal.

Dra. María Elena Torres Pérez. Facultad de Arquitectura. Universidad Autónoma de Yucatán, Mérida. México.

\section{TEXTOS VIVOS}

Juan José López de la Cruz. Escuela Técnica Superior de Arquitectura. Universidad de Sevilla. España.

Dr. Francisco Javier Montero Fernández. Escuela Técnica Superior de Arquitectura. Universidad de Sevilla. España. Dra. Esther Mayoral Campa. Escuela Técnica Superior de Arquitectura. Universidad de Sevilla. España. 


\section{SERVICIOS DE INFORMACIÓN}

\section{CALIDAD EDITORIAL}

La Editorial Universidad de Sevilla cumple los criterios establecidos por la Comisión Nacional Evaluadora de la Actividad Investigadora para que lo publicado por el mismo sea reconocido como "de impacto" (Ministerio de Ciencia e Innovación, Resolución 18939 de 11 de noviembre de 2008 de la Presidencia de la CNEAI, Apéndice I, BOE n² 282, de 22.11.08).

La Editorial Universidad de Sevilla forma parte de la U.N.E. (Unión de Editoriales Universitarias Españolas) ajustándose al sistema de control de calidad que garantiza el prestigio e internacionalidad de sus publicaciones.

PUBLICATION QUALITY

The Editorial Universidad de Sevilla fulfils the criteria established by the National Commission for the Evaluation of Research Activity (CNEAI) so that its publications are recognised as "of impact" (Ministry of Science and Innovation, Resolution 18939 of 11 November 2008 on the Presidency of the CNEAl, Appendix I, BOE No 282, of 22.11.08).

The Editorial Universidad de Sevilla operates a quality control system which ensures the prestige and international nature of its publications, and is a member of the U.N.E. (Unión de Editoriales Universitarias Españolas-Union of Spanish University Publishers).

Los contenidos de la revista PROYECTO, PROGRESO, ARQUITECTURA aparecen en:

bases de datos: indexación
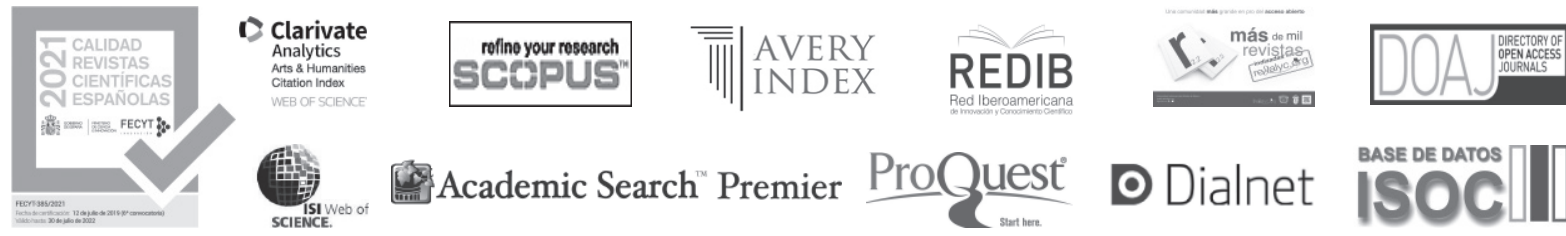

D Dialnet

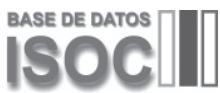

SELLO DE CALIDAD EDITORIAL FECYT 2019, 2020, 2021. Cuartil C2.

WoS. Arts \& Humanities Citation Index. JCl: 0,58. Cuartil Q2. Architecture

SCOPUS: SJR (2019): 0.11, H index: 2. Cuartil Q4

AVERY. Avery Index to Architectural Periodicals

REBID. Red Iberoamericana de Innovación y Conocimiento Científico. Cuartil Q2.

EBSCO. Fuente Académica Premier

EBSCO. Art Source

DOAJ, Directory of Open Access Journals

PROQUEST (Arts \& Humanities, full text)

DIALNET

ISOC (Producida por el CCHS del CSIC)

DRIJ. Directory of Research Journals Indexing

\section{catalogaciones: criterios de calidad}

RESH (Revistas Españolas de Ciencias Sociales y Humanidades).

Catálogos CNEAl (16 criterios de 19). ANECA (18 criterios de 21). LATINDEX (35 criterios sobre 36).

DICE (CCHS del CSIC, ANECA).

MIAR, Matriu d'Informació per a l'Avaluació de Revistes. IDCS 2018: 10,500. Campo ARQUITECTURA

CLASIFICACIÓN INTEGRADA DE REVISTAS CIENTÍFICAS (CIRC-CSIC): A

ERIHPLUS

SCIRUS, for Scientific Information.

ULRICH'S WEB, Global Serials Directory.

ACTUALIDAD IBEROAMERICANA.

\section{catálogos on-line bibliotecas notables de arquitectura:}

CLIO. Catálogo on-line. Columbia University. New York HOLLIS. Catálogo on-line. Harvard University. Cambridge. MA

SBD. Sistema Bibliotecario e Documentale. Instituto Universitario di Architettura di Venezia OPAC. Servizi Bibliotecari di Ateneo. Biblioteca Centrale. Politecnico di Milano

COPAC. Catálogo colectivo (Reino Unido)

SUDOC. Catálogo colectivo (Francia)

ZBD. Catálogo colectivo (Alemania)

REBIUN. Catálogo colectivo (España)

OCLC. WorldCat (Mundial) 
EVALUACIÓN EXTERNA POR PARES Y ANÓNIMA.

El Consejo Editorial remitirá el artículo a dos expertos revisores anónimos dentro del campo específico de investigación y crítica de arquitectura, según el modelo doble ciego.

El director de la revista comunicará a los autores el resultado motivado de la evaluación por correo electrónico, en la dirección que éstos hayan utilizado para enviar el artículo. El director comunicará al autor principal el resultado de la revisión (publicación sin cambios; publicación con correcciones menores; publicación con correcciones importantes; no aconsejable para su publicación), así como las observaciones y comentarios de los revisores.

Si el manuscrito ha sido aceptado con modificaciones, los autores deberán reenviar una nueva versión del artículo, atendiendo a las demandas y sugerencias de los evaluadores externos. Los artículos con correcciones importantes serán remitidos al Consejo Asesor para verificar la validez de las modificaciones efectuadas por el autor. Los autores pueden aportar también una carta al Consejo Editorial en la que indicarán el contenido de las modificaciones del artículo. Los artículos con correcciones importantes serán remitidos al Consejo Asesor para verificar la validez de las modificaciones efectuadas por el autor.

\section{DECLARACIÓN ÉTICA SOBRE PUBLICACIÓN Y MALAS PRÁCTICAS}

La revista PROYECTO, PROGRESO, ARQUITECTURA (PPA) está comprometida con la comunidad académica en garantizar la ética y calidad de los artículos publicados. Nuestra revista tiene como referencia el Código de Conducta y Buenas Prácticas que, para editores de revistas científicas, define el COMITÉ DE ÉTICA DE PUBLICACIONES (COPE).

Así nuestra revista garantiza la adecuada respuesta a las necesidades de los lectores y autores, asegurando la calidad de lo publicado, protegiendo y respetando el contenido de los artículos y la integridad de los mismo. El Consejo Editorial se compromete a publicar las correcciones, aclaraciones, retracciones y disculpas cuando sea preciso.

En cumplimiento de estas buenas prácticas, la revista PPA tiene publicado el sistema de arbitraje que sigue para la selección de artículos así como los criterios de evaluación que deben aplicar los evaluadores externos -anónimos y por pares, ajenos al Consejo Editorial-. La revista PPA mantiene actualizados estos criterios, basados exclusivamente en la relevancia científica del artículo, originalidad, claridad y pertinencia del trabajo presentado.

Nuestra revista garantiza en todo momento la condifencialidad del proceso de evaluación: el anonimato de los evaluadores y de los autores; el contenido evaluado; los informes razonados emitidos por los evaluadores y cualquier otra comunicación emitida por los consejos Editorial, Asesor y Científico si así procediese.

Igualmente quedan afectados de la máxima confidencialidad las posibles aclaraciones, reclamaciones o quejas que un autor desee remitir a los comités de la revista o a los evaluadores del artículo.

La revista PROYECTO, PROGRESO, ARQUITECTURA (PPA) declara su compromiso por el respeto e integridad de los trabajos ya publicados. Por esta razón, el plagio está estrictamente prohibido y los textos que se identifiquen como plagio o su contenido sea fraudulento, serán eliminados o no publicados por la revista PPA. La revista actuará en estos casos con la mayor celeridad posible. Al aceptar los términos y acuerdos expresados por nuestra revista, los autores han de garantizar que el artículo y los materiales asociados a él son originales o no infringen derechos de autor. También los autores tienen que justificar que, en caso de una autoría compartida, hubo un consenso pleno de todos los autores afectados y que no ha sido presentado ni publicado con anterioridad en otro medio de difusión.

\section{EXTERNAL ANONYMOUS PEER REVIEW.}

Editorial Board will be sent to two anonymous experts, within the specific field of architectural investigation and critique, for a double blind review.

The Director of the journal will communicate the result of the reviewers evaluations to the authors by electronic mail, to the address used to send the article. The Director will communicate the result of the review (publication without changes; publication with minor corrections; publication with significant corrections; its publication is not advisable), as well as the observations and comments of the reviewers, to the main author.

If the manuscript has been accepted with modifications, the authors will have to resubmit a new version of the article, addressing the requirements and suggestions of the external reviewers. The articles with corrections will be sent to Advisory Board for verification of the validity of the modifications made by the author. The authors can also send a letter to the Editorial Board, in which they will indicate the content of the modifications of the article.

\section{ETHICS STATEMENT ON PUBLICATION AND BAD PRACTICES} PROYECTO, PROGRESO ARQUITECTURA (PPA) makes a commitment to the academic community by ensuring the ethics and quality of its published articles. As a benchmark, our journal uses the Code of Conduct and Good Practices which, for scientific journals, is defined for editors by the PUBLICATION ETHICS COMMITTEE (COPE).

Our journal thereby guarantees an appropriate response to the needs of readers and authors, ensuring the quality of the published work, protecting and respecting the content and integrity of the articles. The Editorial Board will publish corrections, clarifications, retractions and apologies when necessary.

In compliance with these best practices, PPA has published the arbitration system that is followed for the selection of articles as well as the evaluation criteria to be applied by the anonymous, external peer-reviewers. PPA keeps these criteria current, based solely on the scientific importance, the originality, clarity and relevance of the presented article.

Our journal guarantees the confidentiality of the evaluation process at all times: the anonymity of the reviewers and authors; the reviewed content; the reasoned report issued by the reviewers and any other communication issued by the editorial, advisory and scientific boards as required.

Equally, the strictest confidentiality applies to possible clarifications, claims or complaints that an author may wish to refer to the journal's committees or the article reviewers.

PROYECTO, PROGRESO ARQUITECTURA (PPA) declares its commitment to the respect and integrity of work already published. For this reason, plagiarism is strictly prohibited and texts that are identified as being plagiarized, or having fraudulent content, will be eliminated or not published in PPA. The journal will act as quickly as possible in such cases. In accepting the terms and conditions expressed by our journal, authors must guarantee that the article and the materials associated with it are original and do not infringe copyright. The authors will also have to warrant that, in the case of joint authorship, there has been full consensus of all authors concerned and that the article has not been submitted to, or previously published in, any other media. 


\section{emergencias del espacio común}

índice

editorial

¿CÓMO VIVIREMOS TODOS JUNTOS? MENSAJES DESDE EL INTERIOR DE LA ARQUITECTURA /

HOW WILL WE LIVE ALL TOGETHER? MESSAGES FROM INSIDE ARCHITECTURE

Miguel Ángel de la Cova Morillo-Velarde - (DOl: http://dx.doi.org/10.12795/ppa.2021.i25.09)

artículos

LA INVENCIÓN DEL DESIERTO. ARTE Y ARQUITECTURA DESDE LA COSTA PERUANA / INVENTION OF THE DESERT. ART AND ARCHITECTURE FROM THE PERUVIAN COAST

Octavio Montestruque Bisso; Richard Asto Altamirano - (DOl: http://dx.doi.org/10.12795/ppa.2021.i25.01)

PROYECTO RIIS: UN HAPPENING PARA LA VIDA SOCIAL /

RIIS PROJECT: A HAPPENING FOR SOCIAL LIFE

Juan José Tuset Davó - (D0l: http://dx.doi.org/10.12795/ppa.2021.i25.02)

PLAYGROUNDS Y ESPACIO COMÚN. A PROPÓSITO DEL JUEGO EN LA CIUDAD SUSPENDIDA / PLAYGROUNDS AND COMMON SPACE. ON PLAYING IN THE SUSPENDED CITY

José Parra-Martínez; Nicolás Stutzin-Donoso; Juan Manuel López-Carreño - (DOl: http://dx.doi.org/10.12795/ppa.2021.i25.03)

LA CALLE COMO ESCENOGRAFÍA URBANA. LAS TRANSFORMACIONES DE LARIOS Y ALCAZABILLA EN EL SIGLO XX / THE STREET AS URBAN SCENOGRAPHY. THE TRANSFORMATIONS OF CALLE LARIOS AND CALLE ALCAZABILLA IN THE TWENTIETH CENTURY

Luisa Alarcón González; Francisco Javier Montero-Fernández - (D0l: http://dx.doi.org/10.12795/ppa.2021.i25.04)

DEL BRICOLAJE AL TALLER O EL ESPACIO DE LA TRANSFORMACIÓN EN FRANCIA /

FROM DO-IT-YOURSELF TO THE WORKSHOP, OR THE TRANSFORMATION SPACE IN FRANCE

Ophelia Mantz - (DOI: http://dx.doi.org/10.12795/ppa.2021.i25.05)

reseña bibliográfica TEXTOS VIVOS

IÑAKI ÁBALOS: PALACIOS COMUNALES ATEMPORALES. GENEALOGÍA Y ANATOMÍA

Daniel Díez Martínez - (DOl: http://dx.doi.org/10.12795/ppa.2021.i25.06)

LE CORBUSIER: ¿CAÑONES, MUNICIONES? IGRACIAS! VIVIENDAS... POR FAVOR JORGE TORRES CUECO Y JUAN CALATRAVA: UNA EXPOSICIÓN, UN PABELLÓN Y UN LIBRO: LE CORBUSIER, 1937-1938

Ricardo Sánchez Lampreave - (DOI: http://dx.doi.org/10.12795/ppa.2020.i25.07)

VICTORIANO SAINZ GUTIÉRREZ: ALDO ROSSI Y SEVILLA. EL SIGNIFICADO DE UNOS VIAJES

José lgnacio Linazasoro Rodríguez - (DOl: http://dx.doi.org/10.12795/ppa.2021.i25.08) 


\title{
LA INVENCIÓN DEL DESIERTO. ARTE Y ARQUITECTURA DESDE LA COSTA PERUANA
}

\author{
INVENTION OF THE DESERT. ART AND ARCHITECTURE FROM THE PERUVIAN COAST
}

Octavio Montestruque Bisso (https://orcid.org/0000-0002-6211-4789)

Richard Asto Altamirano (https://orcid.org/0000-0003-4332-2977)

RESUMEN Si pensamos que la selva peruana es vegetación y los Andes son topografía, a la costa la caracterizamos como espacio o vacío esperando ser delimitado. En la segunda mitad del siglo XX, artistas y arquitectos peruanos reflexionan sobre las zonas desérticas alejadas de la ciudad construyendo una narrativa sobre el paisaje. El desierto es conceptualizado como una entidad abstracta, casi como un espejismo de la realidad que se está construyendo en la ciudad. El objetivo del escrito es dar lectura de un paisaje que ha sido idealizado por la alta cultura a pesar de ser una realidad urbana precaria que representa más del $60 \%$ de la extensión de Lima Metropolitana, reforzando la tensión entre las categorías de centro y periferia. Más allá de las posibilidades plásticas, la lectura del desierto nos permite centrar el tema con una mirada de actualidad que ayude a construir una ciudad contemporánea y equitativa, manteniendo los valores espaciales y sociales que corresponden al paisaje y el territorio en el cual habitamos. Recordemos que Lima, la ciudad más grande y poblada del Perú, con casi 10 millones de habitantes, es una de las metrópolis más grandes del mundo construidas en un desierto.

PALABRAS CLAVE desierto; utopía; arquitectura peruana; identidad; paisaje; Lima

SUMMARY We think about the Peruvian rainforest as vegetation and the Andes as topography, but we characterize the coast as a space or emptiness waiting to be defined. In the second half of the twentieth century, Peruvian artists and architects reflect on the desert areas far from the city forming a narrative about the landscape. The desert is conceptualized as an abstract entity, almost as a mirage of the reality that is being built in the city. The objective of the paper is to offer a reading about a landscape that has been idealized by high culture despite being a precarious urban reality that represents more than $60 \%$ of the extension of Metropolitan Lima, reinforcing the tension between the categories of center and outskirts. Beyond the plastic possibilities, a reading about the desert allows us to focus on a current perspective that helps to build a contemporary and equitable city, maintaining the spatial and social values corresponding to the landscape and the territory in which we live. Remember that Lima, the largest and most populous city in Peru, with almost 10 million inhabitants, is one of the largest metropolises in the world built on a desert.

KEYWORDS desert, utopia, Peruvian architecture, identity, landscape, Lima

Persona de contacto / Corresponding author: omontest@ulima.edu.pe. Área de Proyectos e Historia y Teoría de la Arquitectura. Universidad de Lima. Perú. 


\section{NO TODO ES DESIERTO}

$\mathrm{H}$ ablar de paisaje es complejo porque el concepto mismo y su percepción cambia a lo largo del tiempo con la sociedad y la cultura. Su construcción es producto de la interacción entre el ser humano y el ambiente natural, donde la coexistencia da origen a las civilizaciones y genera sus desarrollos. Como explican varios autores contemporáneos, "el paisaje está intimamente ligado a la percepción del ser humano sobre el medio ambiente, percepción no exenta de una carga estética"1.

La transformación del medio ambiente para garantizar dicha coexistencia convierte al paisaje en un artificio. Es un proyecto, una invención que incorpora las ideas y percepciones de un grupo humano en un determinado momento histórico. Podemos hacer la distinción entre paisaje y medio ambiente, diciendo que el primero "es 10 que conservamos en la memoria luego de haber dejado de mirar", mientras que el segundo concepto "trata de dar una lectura objetiva de lo que nos rodea"2. La complejidad en su manejo radica en la comprensión de sus relaciones y en su lectura como reflejo del pensamiento humano, en la adecuación de la naturaleza a su cosmovisión y a sus necesidades de sobrevivencia.

Si bien el discurso del desierto ha sido abordado por la arquitectura limeña en las últimas décadas, este texto propone una lectura del paisaje como referencia para el arte y la arquitectura, que lo interpreta como algo idealizado y estático. Sin embargo, existe también el desierto como reflejo de la realidad urbana, desbordada desde hace varias décadas en la capital peruana, y que se presenta como un espacio cambiante, periférico y precario. La habitabilidad futura del desierto como espacio común pasa justamente por su reconocimiento como paisaje en construcción, como algo que "redefine el mundo no solamente por sus características físicas y experienciales, sino también por su contenido eidético, es decir, su capacidad para contener y expresar ideas"3. 
1. Mapa de Lima Metropolitana, del territorio correspondiente a sus tres valles y el inicio de la cordillera. 2. Índice de vegetación de Lima Metropolitana entre marzo de 2001 y abril de 2019. Los mapas muestran el incremento del proceso de desertificación de la ciudad.
Si se piensa en el paisaje peruano, el desierto no aparece como una referencia inmediata ${ }^{4}$. El desierto peruano es una estrecha franja que se extiende entre el océano Pacífico y la cordillera de los Andes como una continuación del desierto de Atacama. Esta franja desértica se encuentra interrumpida por diversos paisajes como humedales, bosques secos y valles. En uno de ellos, el valle del Rímac, se funda Lima, que ahora se extiende por el valle de Chillón, al norte, y el valle de Lurín, al sur.

Cuando Pizarro llega a América decide establecer en Lima el centro administrativo del continente no solo por la posibilidad de conectarse con Europa por vía marítima, sino también porque encuentra un lugar fértil, densamente poblado, de clima amable y con caminos que permiten recorrer el territorio en todas sus direcciones ${ }^{5}$.

Por este motivo, la capital peruana es por muchos años considerada una ciudad jardín. Los cronistas de la colonia presentan este territorio como un espacio heterogéneo. De hecho, "el suelo de Lima es 18\% arenal, 29\% valle y 53\% cordillera (roca)"6. La idea de la ciudad jardín es una construcción ideológica de la élite limeña del siglo XIX7 , que imagina un territorio parecido al que encontraron los europeos a su llegada a tierras americanas. A pesar de ello, el discurso del desierto aparece como constante en el arte y la arquitectura desde la segunda mitad del siglo XX como un escenario idílico. El desierto se convierte en una invención que dista de la conformación real del territorio, pero que nos da algunas señales sobre el actual proceso de desertificación ${ }^{8}$, factor preocupante y no romántico como se ha querido concebir (figuras 1 y 2).

\section{DENTRO Y FUERA}

A inicios del siglo XX el proceso modernizador impulsa el crecimiento de la capital. A partir de 1940 la población crece drásticamente; pasa de tener 645000 habitantes a bordear los 5 millones solo cuatro décadas después ${ }^{9}$. Durante este periodo la ciudad se expande urbanizando las áreas agrícolas, ocupando las zonas áridas y destruyendo los sistemas de irrigación del valle que construyeron los antiguos peruanos, para quienes "el desierto más próximo no fue (...) un imaginario dominante y romántico al cual se debía mantener yermo, sino transformarlo en vida. No la esterilidad desértica, sino la abundancia voluptuosa del valle y sus lomas. El 'oasis' de las élites arquitectónicas peruanas como universo y no como excepción"10 (figura 3).

La separación e inequidad en la ocupación del territorio instaura una relación de centro-periferia, una constante en la organización espacial que ha tenido fuertes repercusiones en la manera de percibirnos como parte de un colectivo. La sociedad y las ciudades son pensadas desde la dicotomía del centro idealizado y la distopía que se construye en la periferia desértica, en muchos casos, como asentamientos populares. Hacia fines del siglo XX el desierto se convierte en una porción importante de la realidad urbana y es considerado como parte del paisaje de la ciudad (figuras 4 y 5).

Una de las primeras lecturas críticas de la relación centro-periferia como reflejo de la dicotomía oasisdesierto la hace el escritor Sebastián Salazar Bondy en el libro Lima la horrible, de 1964. El ensayo busca una posición reivindicatoria de lo indígena -el desierto, la

4. El Perú seguramente es imaginado como un territorio andino, cuna de antiguas civilizaciones. Analizado desde su extensión, el $60 \%$ del territorio es selva amazónica y, a pesar de eso, la Amazonía es un espacio olvidado al hablar de identidad nacional.

5. COGORNO, Gilda; ORTIZ DE ZEVALLOS, Pilar. La Lima que encontró Pizarro. Lima: Taurus, 2018.

6. CASTILLO, Juan Manuel del. Lima la fértil: la inconsistencia del discurso de la ciudad-desierto. En: La Chimenea. Revista de arquitectura [en línea]. 14-12-2014 [consulta: 08-01-2021]. Disponible en: http://revistalachimenea.blogspot.com/2014/12/lima-la-fertil.html?utm_medium=website\&utm_source=archdaily.pe. 7. LUDEÑA, Wiley. Con-cierto de-sierto barroco. En: ARQ, julio 2004, n. ${ }^{\circ}$ 57, pp. 10-13.

8. El proceso de desertificación por el que atraviesan los tres valles de Lima se ha acentuado en los últimos años. El territorio limeño se ha visto afectado por la expansión urbana, sea esta planificada o no. En ambos casos se prioriza el valor del suelo como espacio edificable y no como parte de un territorio que debe ser gestionado a gran escala. Los factores humanos que contribuyen al proceso de desertificación de la costa peruana son, según un informe del Ministerio del Ambiente, la "pérdida de suelos agrícolas de los alrededores de las ciudades, reducción de humedales y superpoblación".

9. PROTZEL, Javier. Continuidades, hibridaciones y rupturas. En: América Latina Hoy, 2001, n. ${ }^{0} 28$, pp. 149-169.

10. CASTILLO, Juan Manuel del, op. cit. supra, nota 6. 

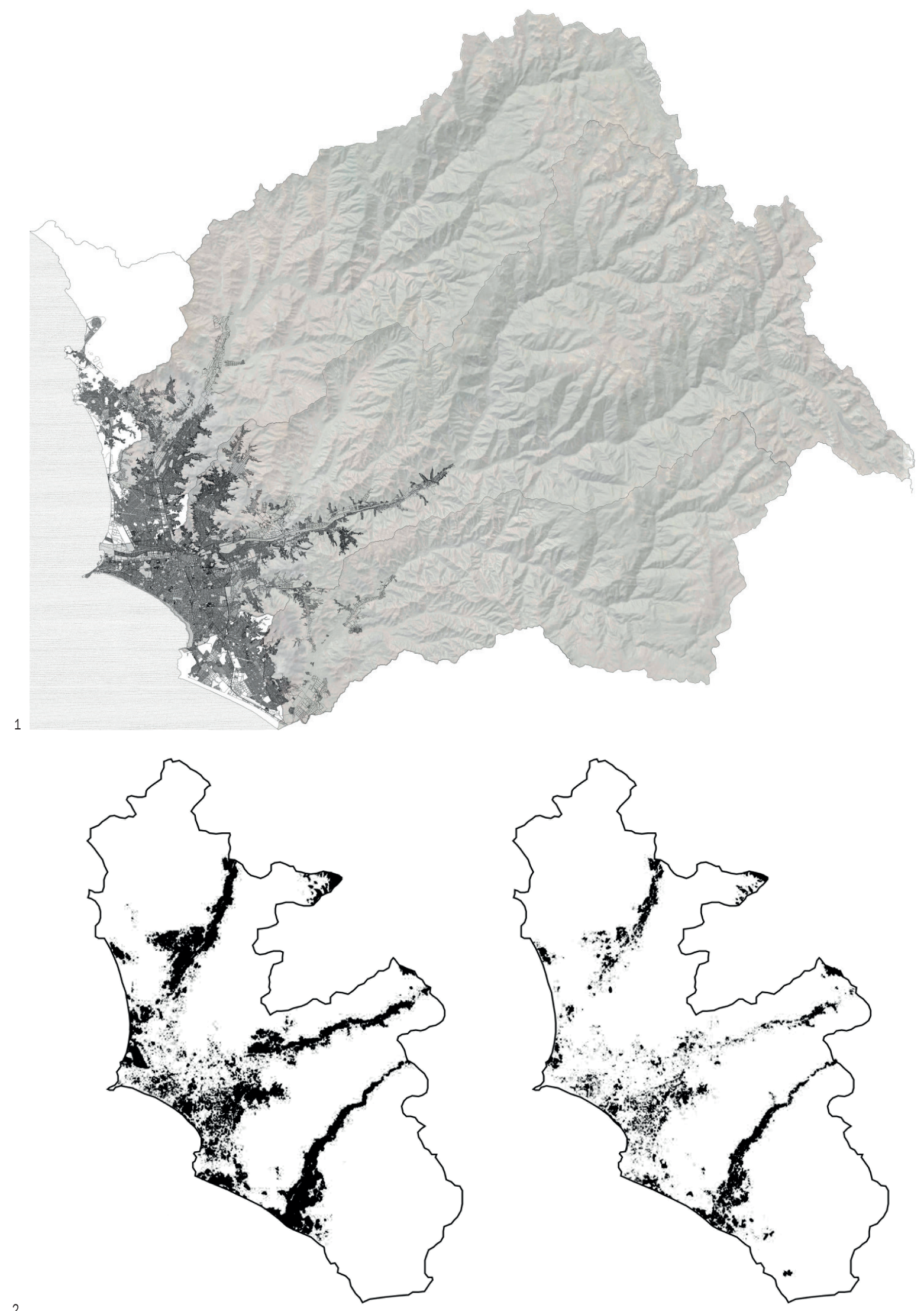
3. Vista satelital de 1974 del territorio que comprende la ciudad de Lima, incluyendo los tres ríos que conforman sus valles y los dos ejes del Camino Inca que lo atraviesan. En la parte superior derecha se ve la expansión de la mancha urbana durante el siglo xx.

4. Vista satelital del centro de Lima. Se pueden distinguir el Cercado, el distrito del Rímac y Barrios Altos, los tres sectores fundacionales de la ciudad colonial. Inicio de los años 2000.

5. Fotografía del Cerro San Cristóbal, ubicado en los distritos del Rímac y San Juan de Lurigancho, en el centro de la ciudad. Se muestra la primera ocupación informal de Lima, el barrio Leticia de 1933. Fotografía de 1955.

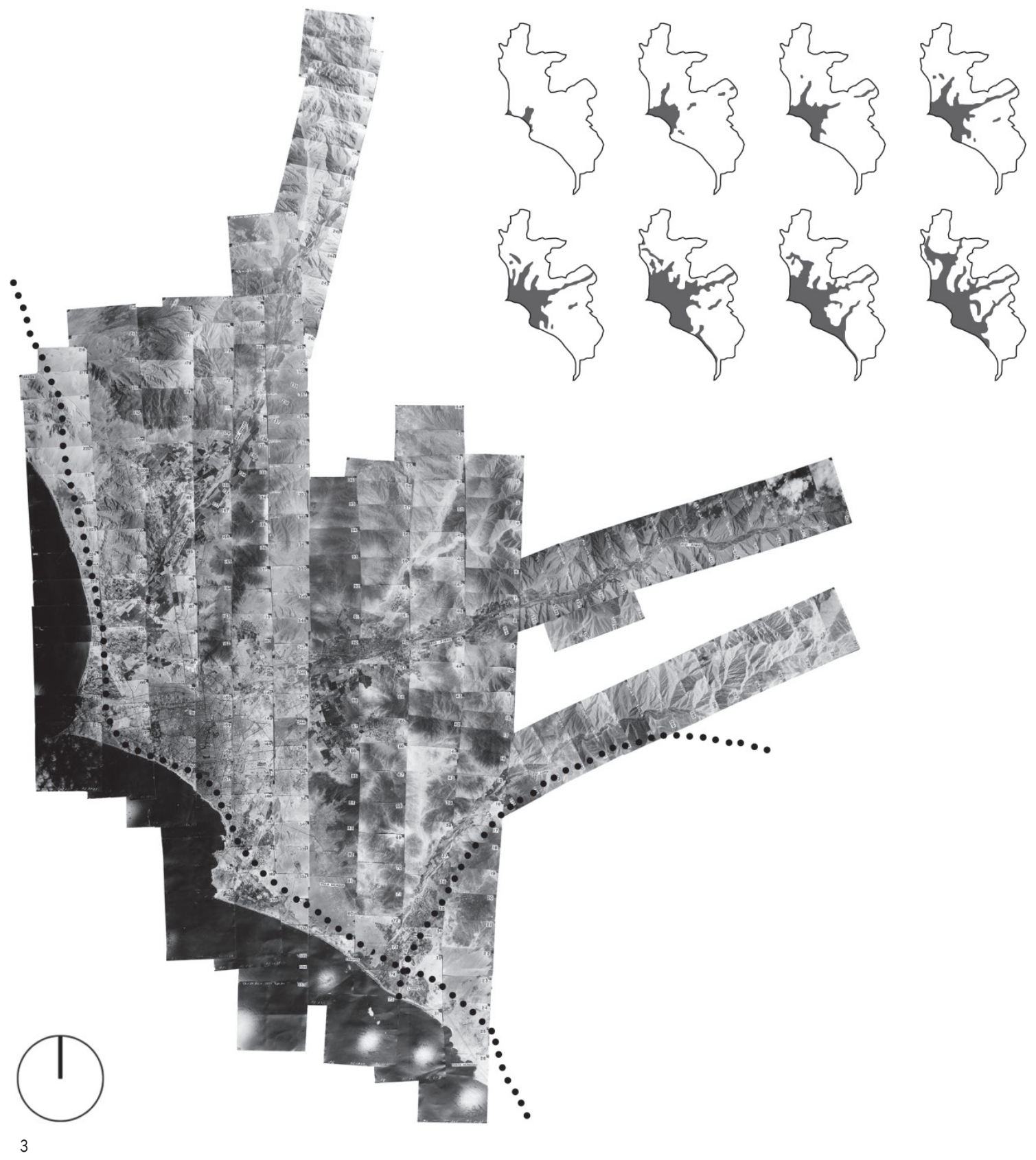




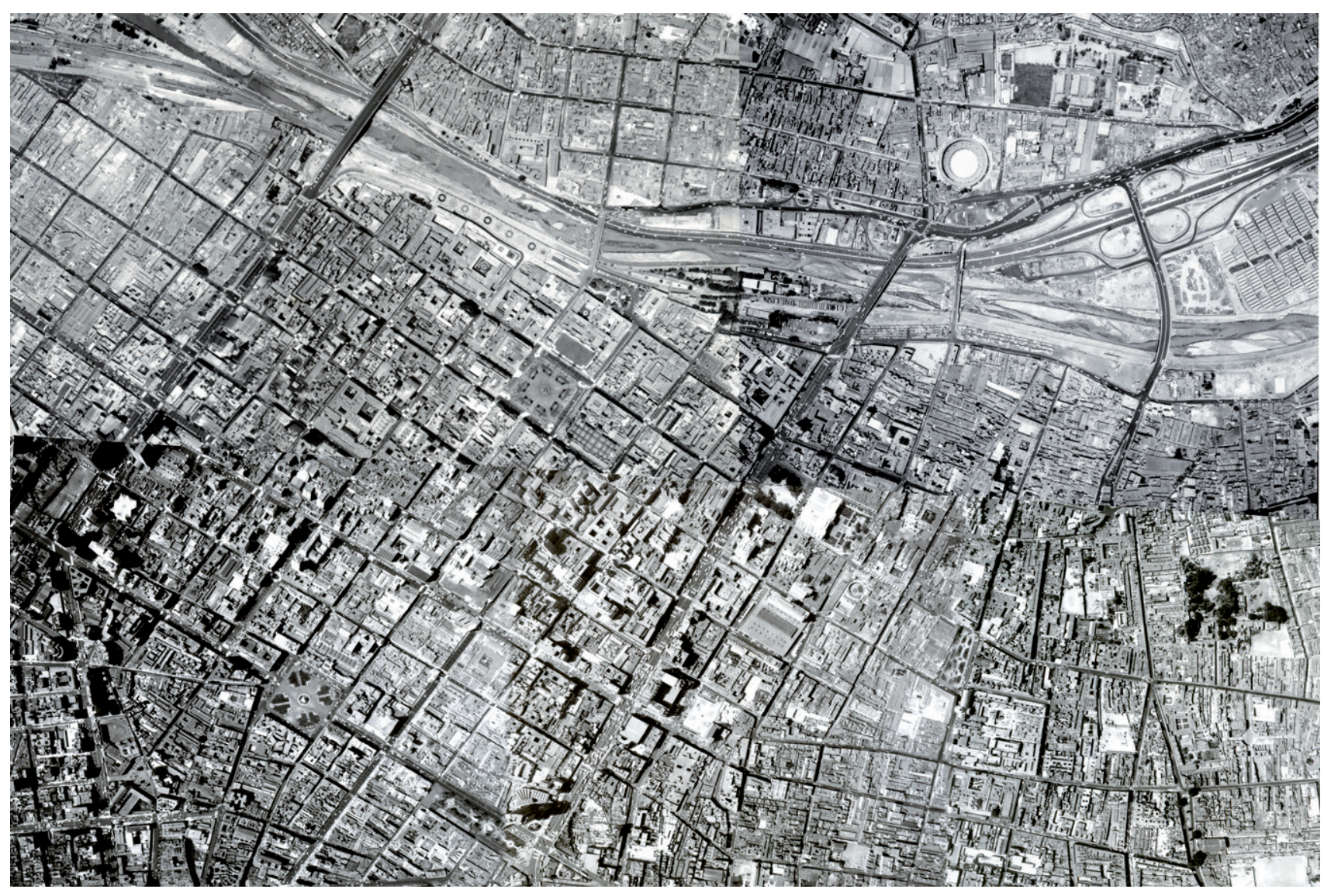

periferia- sobre lo colonial -el oasis, el centro- mediante una lectura crítica de la ciudad. El desierto aparece como una realidad social y cultural, como una construcción mental que tiene características que van más allá de su naturaleza árida y alejada del centro.

Salazar Bondy articula su discurso a partir de la confrontación con la realidad material -llámese paisaje y arquitectura-, así como con la inmaterial, es decir, la sociedad y sus formas de vida ${ }^{11}$, que se manifiesta cuando la ciudad se expande y traspasa las barreras del oasis hacia el desierto. La negación del desierto se presenta como una condición nostálgica del oasis cuando se empieza a resquebrajar la separación entre el centro y la periferia. A pesar de que para fines del siglo XX prácticamente dos terceras partes de la extensión metropolitana están construidas en los cerros y zonas áridas, el paisaje del desierto se idealiza como un espacio periférico que denota un regreso a los orígenes de las civilizaciones de la costa peruana y que posibilita la especulación conceptual en el arte y la arquitectura.

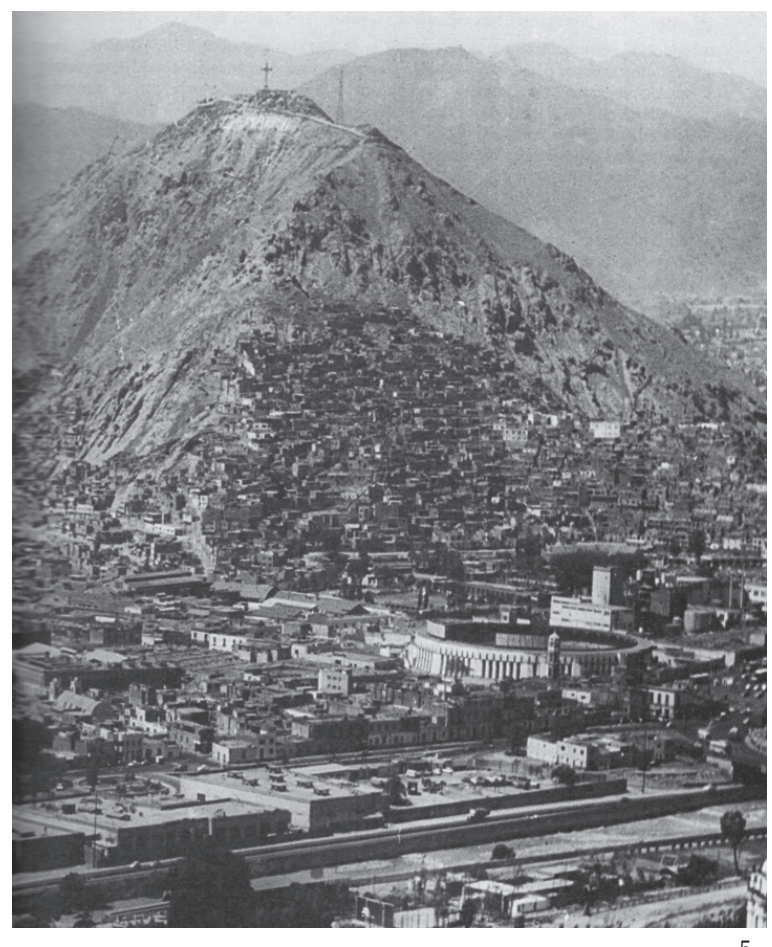


En la segunda mitad del siglo XX algunos artistas buscan en el desierto una conexión con el pasado en un paisaje periférico e idealizado. No es un espacio marginal, sino que toma connotaciones fenomenológicas que calan en lo más profundo de la sensibilidad artística. El desierto se convierte en una invención, en el sentido de que se contrapone a los aspectos europeos que habrían prevalecido en la ciudad colonial y, por lo tanto, tiene la posibilidad de incluir la narrativa de una modernidad fundada en ideas nacionalistas. El desierto no se presenta como una realidad tangible, sino como un constructo mental que permite pensar en términos abstractos un arraigo a lo propio; "en el Perú, la tercera fase de la modernidad se inicia con dos tendencias, una que organiza la dualidad [colonialismo-nacionalismo] de manera tanto vertical como lineal progresiva (...), y otra que, apoyándose en la importancia que el nacionalismo le da a lo nativo, propone una fusión horizontal que no deja de lado la noción de progreso. La primera tendencia presenta lo indígena -la periferia- como humanamente incapaz de conformar otra metrópoli (...). La segunda tendencia plantea la posibilidad de que en lo indígena yazga una energía modernizadora que ha de sobrevivir a una mentalidad no europea que se diluye progresivamente en un proceso ideal de mestizaje"12.

\section{LA IDEALIZACIÓN DE UN PAISAJE}

Contrario a lo que puede suceder en un sistema lógico, la invención del desierto es una condición utópica que tiene valor en cuanto no tiene lugar ${ }^{13}$, un espacio congelado e infinito que sirve de laboratorio para aquello que se va construyendo en la realidad. La memoria es una herramienta que permite filtrar y clasificar los aspectos relevantes desde la propia percepción del entorno; tiene también el potencial de reconstruir el pasado a partir de las co-
6. Fotografía de La Máquina de arcilla, realizada por Emilio Rodríguez Larraín en 1987, ubicada en la playa de Huanchaco, Trujillo, en la costa norte del Perú. nexiones afectivas que puedan suceder en el presente, tal como lo hacía Jorge Eduardo Eielson, artista peruano que, con veinticuatro años, migra a Europa en 1948. Para Eielson, el recuerdo del desierto es el único vínculo que mantiene con el Perú y, por lo tanto, el hilo que lo une con una identidad autóctona. Su obra se basa en conceptos como las huellas del movimiento, el tiempo congelado, la sensación de vacío y la condición de ruina ${ }^{14}$, ideas que se articulan gracias a sus recuerdos de infancia en las playas de Lima.

En la obra abierta Paisaje infinito de la costa peruana, el artista explora el desierto como un territorio actualmente no ocupado, pero que tiene vestigios de la presencia del ser humano debido a los restos que este ha dejado. En sus cuadros matéricos aparece la misma arena del desierto que se hace llevar a Europa ${ }^{15}$; sobre ella, palabras dibujadas, huesos y plumas de aves o trozos de tela manifiestan que la naturaleza se convierte en paisaje -y por lo tanto aparece el espacio- mediante un trabajo casi arqueológico que devela la vida en un lugar donde es aparentemente imposible su existencia ${ }^{16}$.

Emilio Rodríguez Larraín, que investiga sobre la delimitación del espacio para lograr dar escala humana al paisaje inconmensurable, realiza en 1987 La máquina de arcilla, una intervención en la costa norte que utiliza muros de adobe para delimitar espacios cerrados, algunos de ellos inaccesibles, y espacios intermedios que permiten tener una relación entre la persona y el paisaje. Introduce en ella la reflexión sobre el espacio ambivalente, aquel que es interior y exterior al mismo tiempo. Esta es una primera clave en el entendimiento de este paisaje, una serie de espacios delimitados y sugeridos que, mediante su materialidad, reaccionan a las condiciones de la naturaleza, degradándose por el clima y el abandono, convirtiéndose poco a poco en

12. REBAZA SORALUZ, Luis. De ultramodernidades y sus contemporáneos. Lima: Fondo de Cultura Económica, 2017, p. 28.

13. CRUZ, Alberto; IOMMI, Godofredo. Ciudad abierta: de la utopía al espejismo. En: Revista Universitaria, 1983, n. . 9, pp. 17-25.

14. CAVAGNARO, Franco. Más allá de la estética: Jorge Eduardo Eielson frente al legado prehispánico. En: Devenir, enero-junio 2017, n. ${ }^{0} 7$, pp. $101-116$.

15. PADILLA, José lgnacio, ed. Nu/do. Homenaje a Jorge Eduardo Eielson. Lima: Pontificia Universidad Católica del Perú, 2002.

16. Para profundizar sobre el trabajo del artista, se puede revisar el catálogo de la muestra retrospectica Eielson, organizada por el Museo de Arte de Lima entre el 16 de noviembre de 2017 y el 4 de marzo de 2018. Resulta de interés el cuadro Poema, de 1977, donde el artista explora las ideas mencionadas en este texto. 
una ruina moderna erosionada por el desierto infinito y atemporal ${ }^{17}$ (figura 6).

Un elemento adicional que conforma la invención de este paisaje es su ideación como lugar místico. El artista Rafael Hastings, en colaboración con el arquitecto Juvenal Baracco, reflexiona sobre ello con una propuesta conceptual llamada A twe/ve journey plot about levitation, realizada en 1980. Hastings describe la intervención como una acción teatral que sucede en el desierto, a 300 kilómetros al sur de Lima, y que presenta un tránsito de doce semanas a través de las cuales el protagonista juega al límite entre la ficción y la realidad para finalmente levitar fuera de este mundo. Según Hastings, "desde la llegada de los españoles a América, es la primera vez que se trabaja el paisaje (...) con la acción simbólica del hombre como parte de él (...), el paisaje ha sido siempre retratado como una entidad aislada, como naturaleza (...). Como resultante, el espacio es otro y hace frente al tiempo mal repertoriado [sic] del actual asentamiento humano en Latinoamérica, que cada vez es más dependiente del tiempo industrial. El ajuste al tiempo es entonces en este trabajo un ajuste al desierto, a lo divino"18 (figura 7).

La propuesta es presentada con una lámina que incluye una serie de viñetas que describen las escenas imaginadas por Hastings y las estructuras diseñadas por Baracco. Se incorpora, además, un mapa con treinta escenas ubicadas en el territorio y que relacionan al ser humano con la naturaleza. El desierto adquiere valor místico en el momento en el que el ser humano se enfrenta a él y trata de habitarlo. La lectura del paisaje propone un retorno a los orígenes, una relación vital entre el hombre y el vacío con la que se fundamentan las culturas más antiguas del Perú ${ }^{19}$, anunciando un interés por comprender y teorizar sobre el espacio construido en el desierto peruano.

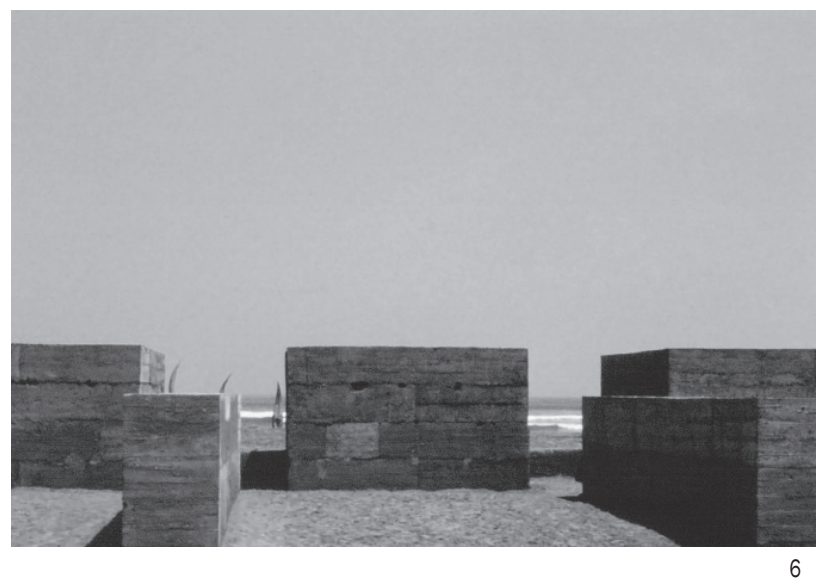

\section{HABITAR EL DESIERTO}

El regreso a los orígenes de la disciplina también significa un regreso a los orígenes de la propia cultura. Juvenal Baracco, por ejemplo, sostiene como hipótesis de trabajo en su taller de la Universidad Ricardo Palma que "es posible concebir toda la problemática arquitectónica universal en el marco del espacio correspondiente al territorio y sociedad peruana. (...). Solo en ese momento la arquitectura será un valor cultural permanente"20.

En la década de 1980 aparecen algunas obras que reúnen estas características como estrategia para abordar la habitabilidad del desierto. Los arquitectos peruanos especulan sobre la posibilidad de actualidad en una arquitectura originaria, especialmente en la que se ubica en la costa peruana. La arquitectura se presenta como una masa abstracta que delimita vacíos dentro del paisaje, donde el leguaje moderno se nutre del arte y la arquitectura antiguos. En este caso, artistas y referentes se encuentran distanciados temporalmente, pero pertenecen al mismo territorio.

17. Para profundizar sobre el trabajo del artista, se puede revisar el catálogo de la muestra retrospectiva Rodríguez Larraín, organizada por el Museo de Arte de Lima entre el 16 de marzo y el 14 de agosto de 2016. Resultan interesantes las obras Refugio de los Andes y La máquina de arcilla, de 1985 y 1987 respectivamente, donde el artista explora las ideas mencionadas en este texto.

18. LÓPEZ, Miguel, ed. Rafael Hastinǵs. El futuro es nuestro y/o por un pasado mejor 1983-1967. Lima: ICPNA, 2004, p. 223.

19. Ídem.

20. BARACC0, Juvenal. Espacio sin límites. Lima: Art Lautrec, 1990, p. 8. 
7. Lámina de la propuesta de Rafael Hastings y Juvenal Baracco, A twelve journey plot about levitation, realizada en 1980.

8. Fotografía de la casa Ghezzi proyectada por Juvenal Baracco en el balneario de Pulpos en 1984, al sur de Lima; vista general de la casa.

9. Planta de la casa Ghezzi.

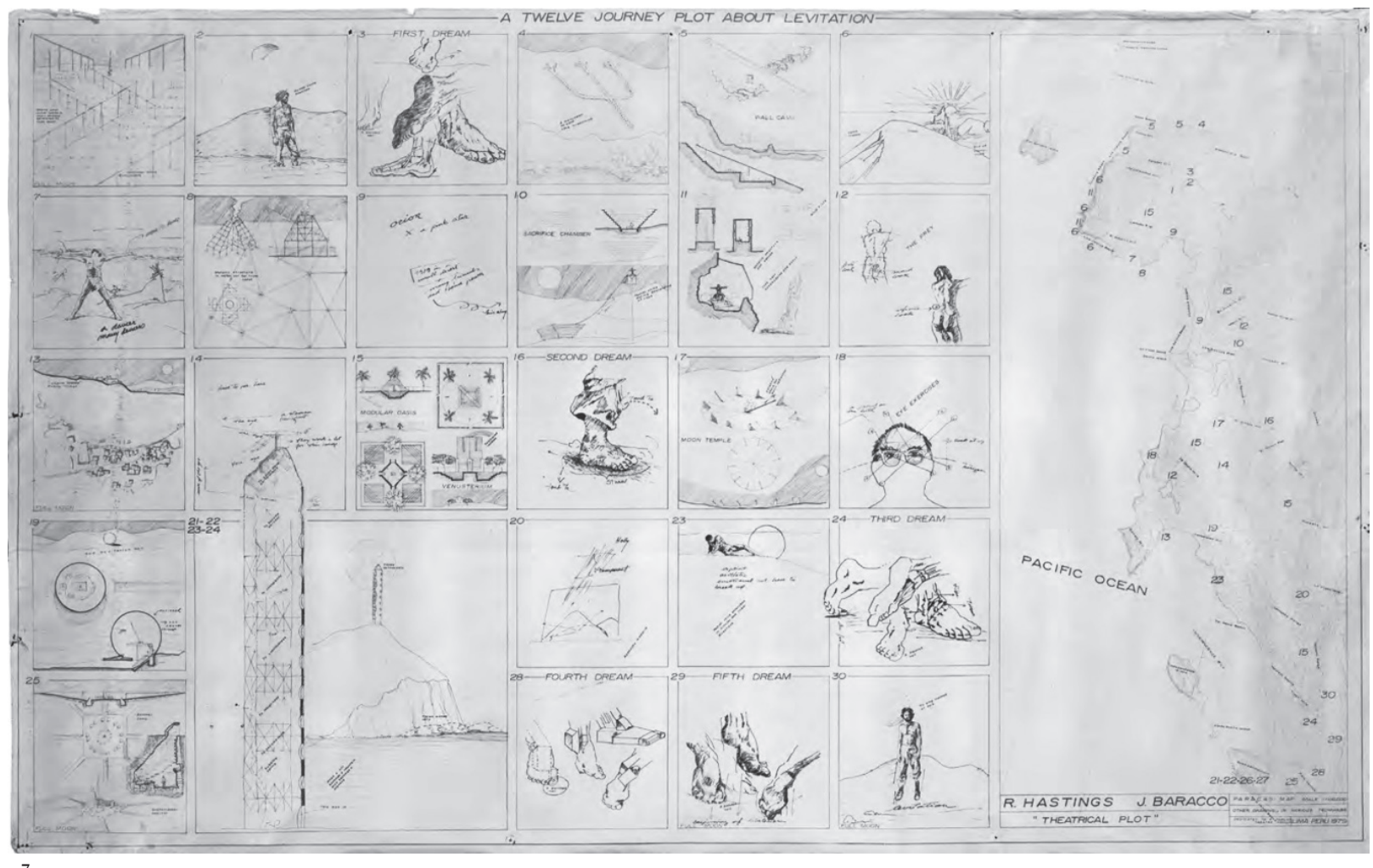

La casa Ghezzi, proyectada en 1984 por Juvenal Baracco, es uno de los ejemplos más notables de intervención en el desierto. Es la primera obra arquitectónica contemporánea que teoriza sobre las relaciones entre el hombre y su paisaje, además de que en su momento gozó de gran difusión por ser un ejemplo de resistencia a la "incómoda sensación de dependencia permanente. Dependencia de imágenes aplicadas a modificar las líneas rigurosas y desnudas que caracterizaron al movimiento moderno"21. Con la casa Ghezzi, Baracco aborda la relación con el paisaje árido del desierto. Toma referencias de la arquitectura austera de orígenes prehispánicos, así como de las ocupaciones informales en las periferias urbanas. El resultado es una construcción que utiliza dos formas contrapuestas: un volumen macizo en forma de U y una estructura de madera rústica. El volumen alberga los espacios de una vivienda tradicional y articula un espacio que, delimitado por la estructura de madera, se relaciona directamente con el paisaje. En este proyecto se busca habitar el desierto inhóspito envolviendo los vacíos que se generan en él (figuras 8 y 9).

La casa Ghezzi no fue concebida como una obra aislada. El arquitecto realiza un conjunto de viviendas que exploran la ocupación del desierto replicando las características del espacio que se define de manera austera, con elementos sencillos y de construcción artesanal. Este 

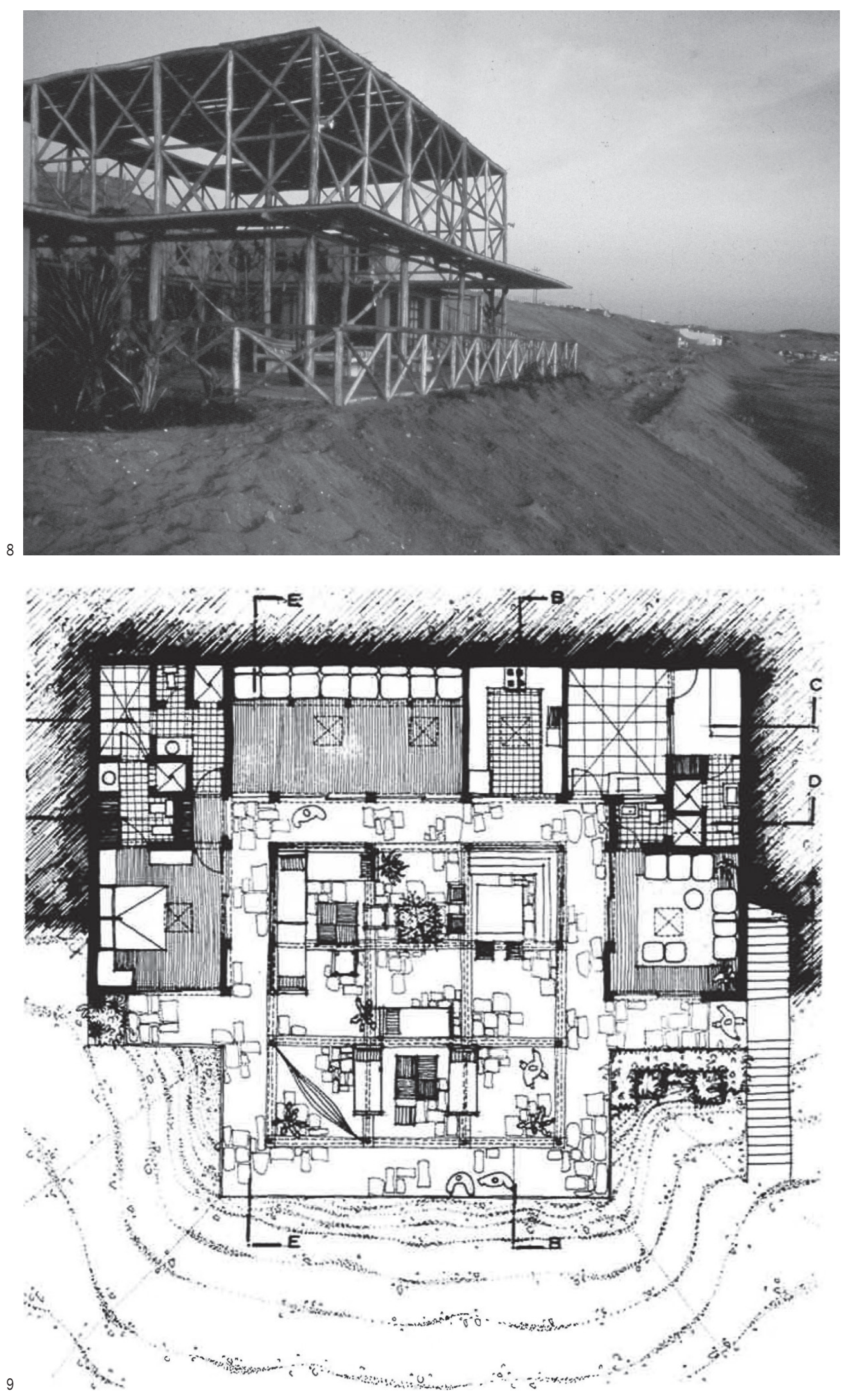


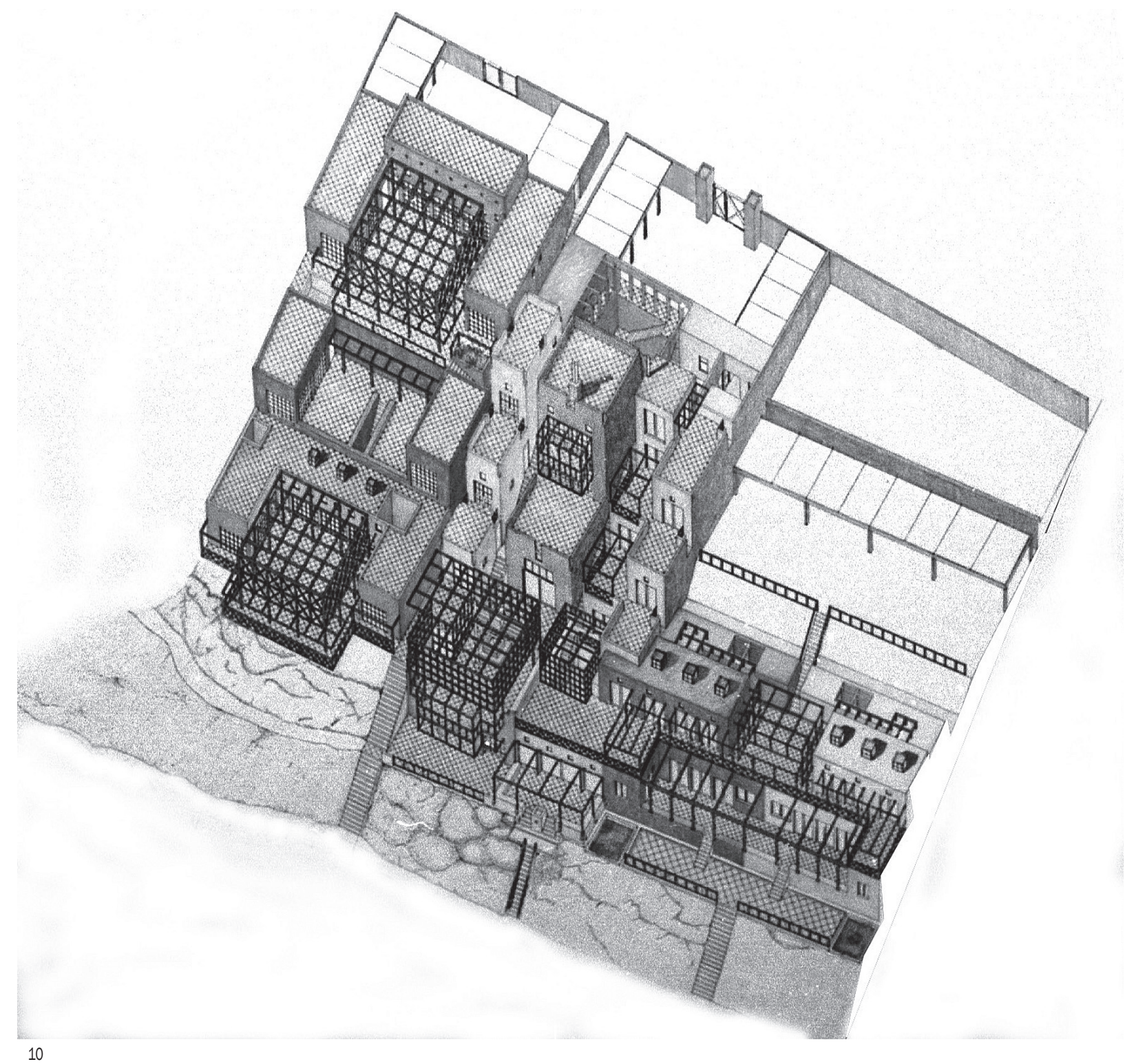

espacio de mediación entre la arquitectura y el paisaje se repite y adapta en el conjunto, construyendo un modelo de urbanización que responde a las condiciones del medio ambiente. Lamentablemente, como veremos más adelante, este sistema de ocupación no se va a replicar en las futuras urbanizaciones de playa, que más bien niegan el desierto y buscan reproducir las características urbanas del oasis. El valor de la propuesta de Baracco radica en el entendimiento del paisaje como una construcción cultural, que en los años en los que proyectaba el conjunto, se veía reflejada en las periferias autoconstruidas de Lima (figura 10).

A mediados de la década de 1980, superados los años del gobierno militar y con el crecimiento del terrorismo en el país, la ocupación de los terrenos a las afueras de la ciudad de Lima se incrementa, ya sea como nuevas invasiones 22 producto de las migraciones internas, o como urbanizaciones cerradas que buscan alejarse de la

22. La ocupación de las zonas periféricas se inicia en 1933 con el barrio Leticia, en el cerro San Cristóbal, en el distrito del Rímac -parte del sector fundacional de la ciudad-. Estas invasiones continúan hasta el día de hoy, pero se detecta un incremento drástico en la década de 1980. 
10. Dibujo del conjunto de casas diseñadas en el balneario de Pulpos, al sur de Lima.

11. Vista satelital del distrito de Asia. Se pueden observar las urbanizaciones privadas que se ubican frente al mar, en claro contraste con el territorio.

ciudad. Mientras que la primera situación es producto de la pobreza y de la marginalidad, la segunda se formaliza mediante la creación de urbanizaciones cerradas y excluyentes. Hacia fines del siglo XX el desierto se revela en dos situaciones simultáneas: como distopía para miles de ciudadanos sin acceso a bienes básicos como la vivienda, y como escenario utópico de fin de semana para un sector rico de la sociedad limeña ${ }^{23}$.

El desarrollo del mercado inmobiliario incentiva la rápida ocupación de las zonas frente al mar al sur de la ciudad, reproduciendo la condición de oasis que presentaba Lima en el siglo XIX y que se compara con el modelo norteamericano de gated community ${ }^{24}$. Se crea así un escenario que responde por negación al desierto, tanto en su dimensión social como natural. Este fenómeno traslada la tipología de vivienda urbana a una condición de periferia sin lograr articular un discurso con el paisaje como se venía haciendo desde hace algunos años en el arte y la arquitectura. La principal característica de estas urbanizaciones es la artificialidad con la que se crean los espacios abiertos y de convivencia, ya sea mediante clubs para los socios, campos de golf o lagunas artificiales, es decir, el verdadero paisaje sirve únicamente como telón de fondo para la creación de una escenografía idílica. El deseo de homogenización dentro de estas urbanizaciones, regidas por duros reglamentos de construcción y comportamien$\mathrm{to}^{25}$, busca crear un mundo interior que representa una negación del exterior del verdadero desierto (figura 11).

Desde la década de 2000, la arquitectura peruana se centra de manera casi exclusiva en el diseño de casas de fin de semana para la élite limeña. Resulta recurrente utilizar el discurso del desierto sin hacer referencia a las corrientes de pensamiento del paisaje contemporáneo, sino más bien como una estrategia de justificación de la libertad compositiva del arquitecto. El desierto se convierte,

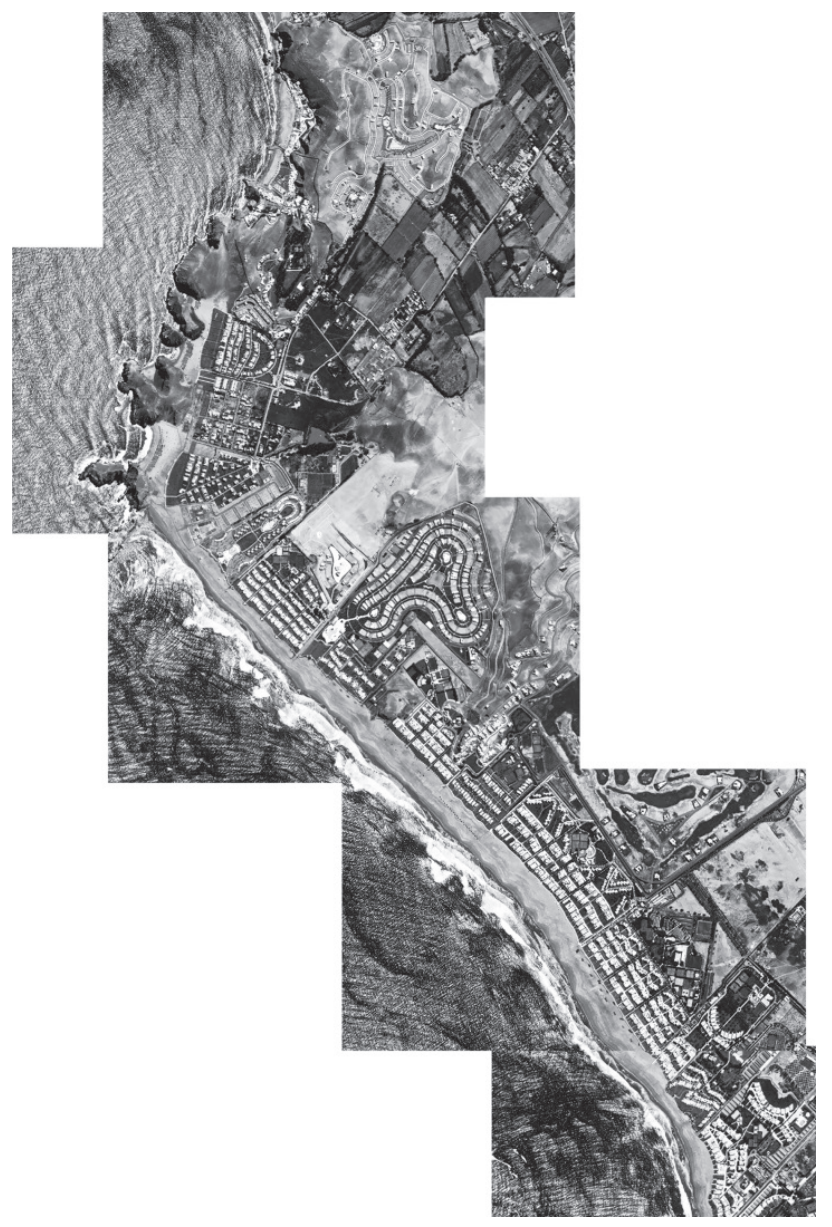

11

23. LUDEÑA, Wiley, op. cit. supra, nota 7.

24. MATTA, Raúl. "Asia” (Lima, Perú), barrios cerrados para vacaciones de lujo. En: L'Ordinaire des Amériques [en línea], 2007 publicado el 6 de diciembre de 2016, n. 207 [consulta: 07-02-2021]. Disponible en: http://journals.openedition.org/orda/3366; DOl: https://doi.org/10.4000/orda.3366.

25. Si bien existen algunas variaciones entre los reglamentos de cada urbanización, en un gran número de ellas se exige el uso de muros enlucidos de blanco, se restringe el uso de algunos materiales expuestos o la incorporación de colores y se regula la altura de cada casa según su cercanía al mar. Además, existen reglamentos de comportamiento que incluyen el uso de uniformes para el personal de servicio de cada familia, así como restricciones sobre el uso de la playa y el acceso al mar en determinados horarios. En otras palabras, se manifiesta un sistema social antiguo, perteneciente al mundo colonial y aristocrático, que estaba durmiendo en la ciudad y que despierta en estas comunidades exclusivas. 


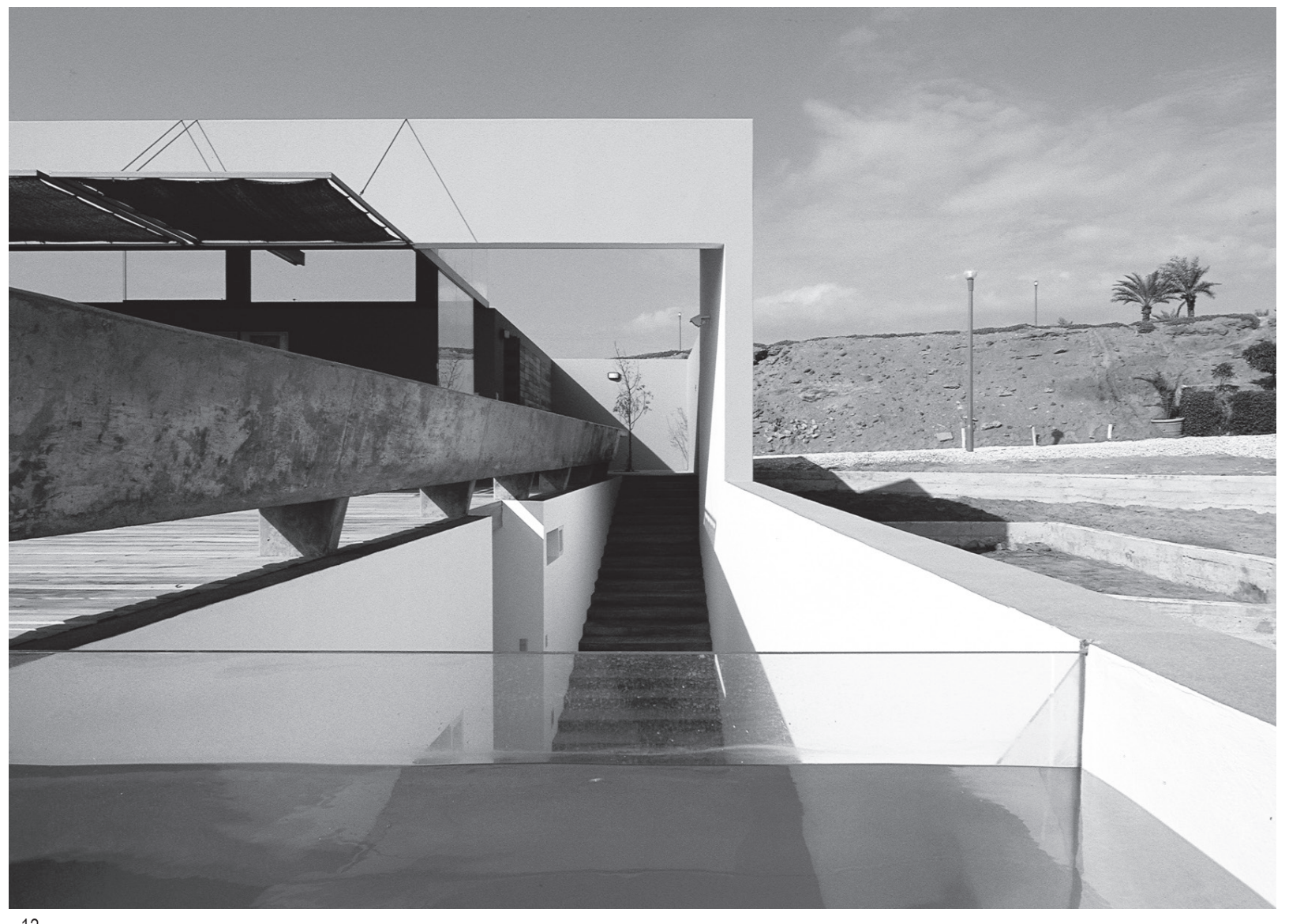

12

erróneamente, en ausencia de contexto y de referencias, lo que motiva una arquitectura formalista que continúa algunas tendencias tardomodernas. Salvo pocas excepciones, la arquitectura que se propone en estos lugares busca reproducir una situación urbana anónima, que se despoja de las posibilidades plásticas, espaciales, temporales y místicas que han resultado de la invención del desierto, recurriendo únicamente a un aparente minimalismo formal y a acabados genéricos de muros enlucidos.

Un cambio surge con las primeras casas que realiza el estudio Barclay \& Crousse ${ }^{26}$ en la playa La Escondida, 100 kilómetros al sur de Lima. En esta urbanización las restricciones constructivas son menores, lo que permite a los arquitectos incorporar el color y materiales expuestos, aunque lo que más destaca en estas casas es la negación de una separación rígida entre interior y exterior para generar espacios intermedios en donde se pueda habitar el paisaje. Para ello, "el esquema mantiene, por un lado, el cerramiento perimetral mientras, por el otro, se invierte completamente: la ubicación de los ambientes es centrípeta con respecto a la ubicación de los vacíos, que son centrífugos"27, expresando también un interés por el vacío de los espacios abiertos que "representa una prolongación hacia el exterior de los espacios principales de la casa"28 (figura 12).

Haciendo referencia al paisaje, Crousse dice que "la visión occidental moderna de la realidad ha puesto el acento sobre el ser y el objeto, mientras que la oriental y la andina privilegian el devenir y la relación"29, argumento que también se podría aplicar para interpretar la arquitectura

26. Estudio dirigido por los arquitectos peruanos Sandra Barclay y Jean Pierre Crousse. Es importante mencionar que ambos han sido alumnos destacados del taller de Juvenal Baracco en la Universidad Ricardo Palma, donde terminaron sus estudios, él en 1987 y ella en 1990. Justamente durante ese periodo, el taller vertical de Baracco hacía especial énfasis en la posibilidad de construir una arquitectura contemporánea con un fuerte arraigo al territorio y sociedad peruana. 27. CACCIATORE, Francesco; FOTI, Fabrizio. Barclay \& Crousse. Segnali di vita tra i due deserti. Siracusa: LetteraVentidue, 2012, p. 13.

28. Ídem.

29. CROUSSE, Jean Pierre, op. cit. supra, nota 1, p. 43. 
12. Fotografía de la casa Equis proyectada por el estudio Barclay \& Crousse en la playa La Escondida entre 2002 y 2003. Se puede ver uno de los espacios intermedios de la casa y su relación con el paisaje. 13. Dibujo de Jean Pierre Crousse del espacio intermedio en la casa Vedoble.

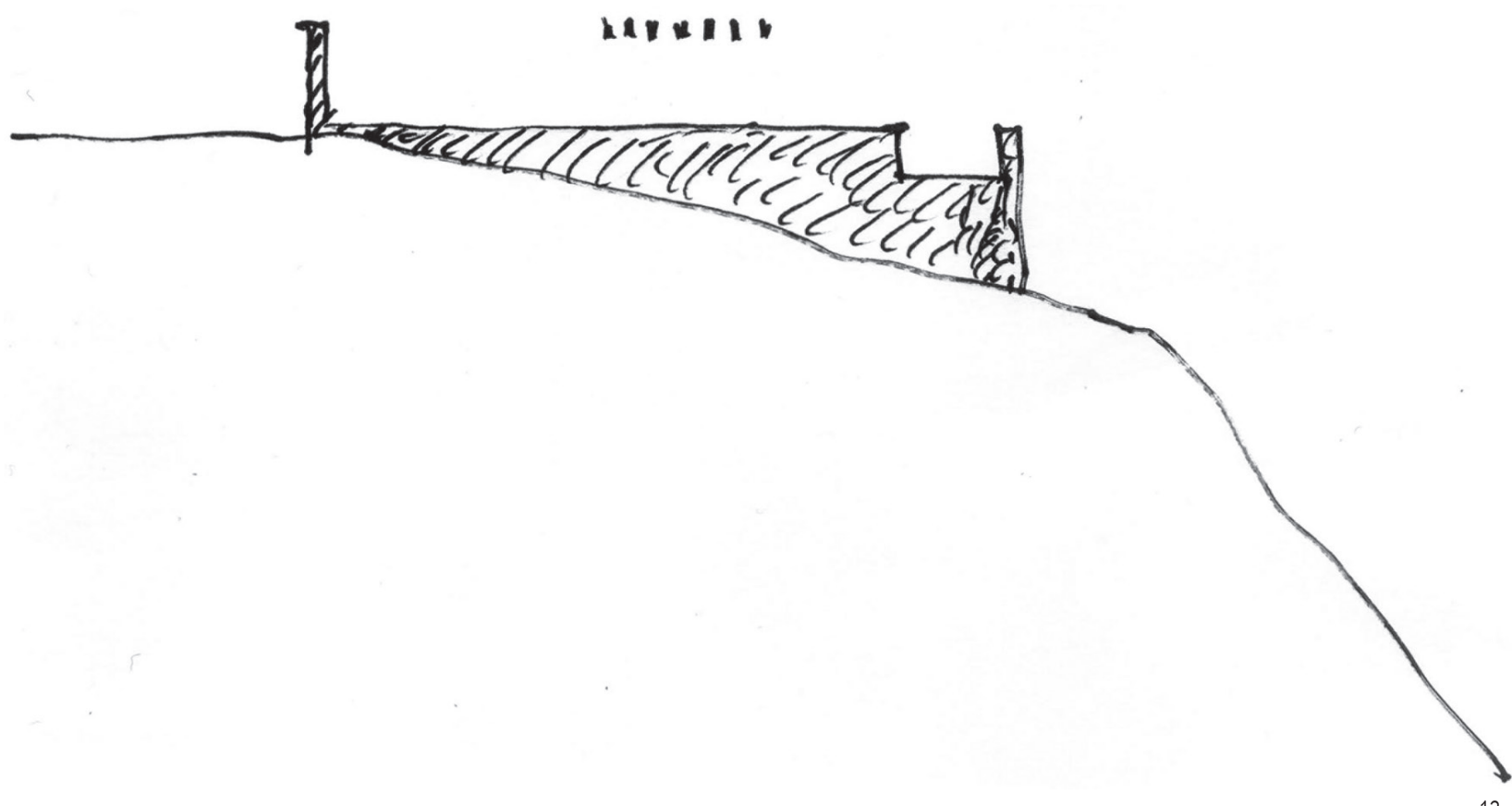

del estudio. En ella es más importante el espacio de relación entre las partes, un tipo de espacio que es abierto, pero que se construye en el interior de los límites de la arquitectura, como lo hacen Rodríguez Larraín o Baracco. En estos espacios intermedios se comprueba la conexión con el paisaje y se logra habitar el desierto (figura 13).

Menos comunes son las intervenciones que se enfrentan al desierto como realidad urbana. En este caso, el desierto sugiere intemperie, pluralidad, escasez de recursos y riqueza de interacciones, condiciones opuestas a la idea de oasis sobre la que se concibe la ciudad colonial.

El desierto también sugiere diversidad cultural debido a las migraciones. Producto de ello surgen barrios autogestionados y autoconstruidos que en muchos casos se consolidan como distritos después de algunas décadas, como es el caso de Comas, ubicado en la zona norte de Lima. La multiculturalidad y tradición de trabajo colaborativo y comunitario en este distrito impulsan la organización de diversos colectivos en el barrio La Balanza, donde, desde el año 2001, se realiza el Festival Internacional de Teatro en Calles Abiertas (FITECA), de gran impacto local y con la participación de centenares de artistas.

Desde el año 2007, el colectivo CITIO Ciudad Transdisciplinar ${ }^{30}$, que luego se transforma en el colectivo CCC -Coordinadora de la Ciudad en Construcción-, desarrolla

30. El colectivo CITIO Ciudad Transdisciplinar está constituido por un grupo de jóvenes arquitectos peruanos comprometidos con el trabajo en "zonas emergentes, vulnerables y conflictivas de Lima, promoviendo la cultura, el arte y la creatividad para la apropiación del espacio público, asumiendo un rol crítico y propositivo frente a los retos del desarrollo humano sostenible y los problemas del habitar" (CITIO Ciudad Transdisciplinar). Su presencia ha sido fundamental para dar forma al Festival Internacional de Teatro en Calles Abiertas (FITECA). Los arquitectos participantes en las dos etapas del proyecto fueron: Etapa 1: Javier Vera, Lucía Nogales, Eleazar Cuadros; Etapa 2: Javier Vera, Eleazar Cuadros, Paula Villar, David Fontcuberta, Exequiel Collantes. Además, colaboran diversos colectivos, el gobierno municipal, universidades y grupos de voluntarios. 
14. Fotografía del Centro Comunitario del Proyecto Fitekantropus en el distrito de Comas, en la zona norte de la ciudad de Lima; vista del espacio interior. 15. Fotografía del Centro Comunitario del Proyecto Fitekantropus en el distrito de Comas, en la zona norte de la ciudad de Lima; vista del conjunto en su contexto urbano.

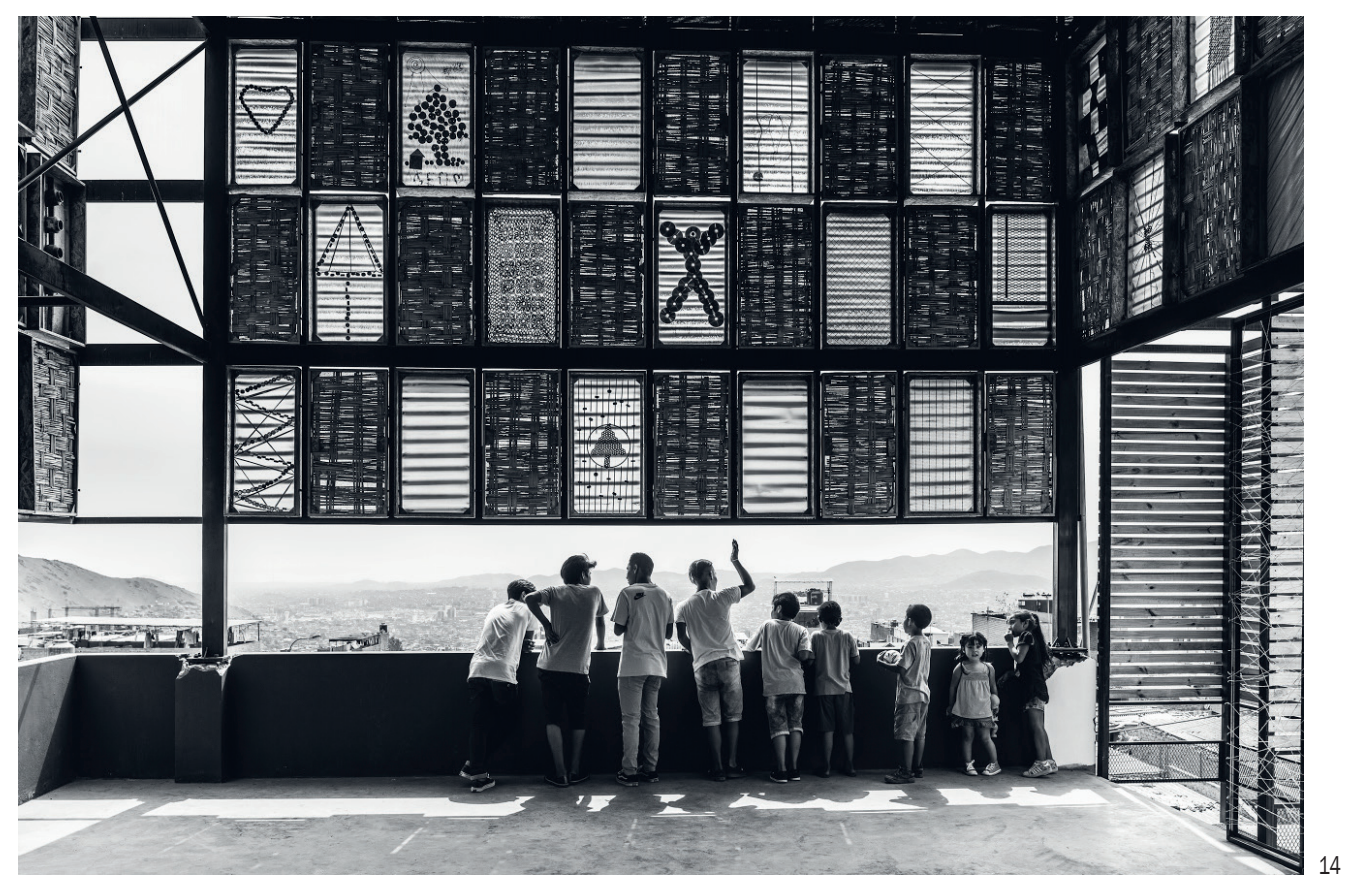

una propuesta para un espacio cultural en la periferia. Se implementa el Proyecto Fitekantropus ${ }^{31}$ trabajando con la simplicidad y síntesis de un proceso de autoconstrucción y las virtudes de la organización en comunidad características de la cultura peruana desde antes de la colonia. La obra propone un espacio para un grupo de personas que se relacionan de manera lúdica con su entorno y se entiende la diversidad como una posibilidad de progreso y modernidad. La estrecha relación entre paisaje, arquitectura y sociedad presenta a Fitekantropus como un proyecto abierto y en expansión por parte de sus usuarios. Esta lectura del contexto como realidad urbana cambiante y heterogénea aporta nuevos valores a la invención del desierto como una utopía que se materializa lentamente en la ciudad: nos permite abrir las posibilidades de una arquitectura contemporánea que puede ser participativa, austera y generadora de cambios efectivos en la vida de los ciudadanos que habitan en las zonas periféricas, no únicamente de aquellos que pueden tener acceso al oasis (figuras 14 y 15).

\section{EL FUTURO DEL DESIERTO}

Habiendo hecho un breve recuento de los intereses que el desierto ha suscitado en el arte y la arquitectura peruana de la segunda mitad del siglo XX, podemos comprobar, en primer lugar, un marcado centralismo limeño. Erróneamente, durante las últimas décadas, los arquitectos de la capital han creado la narrativa del desierto como instrumento de homologación de la arquitectura en el Perú. Inclusive dentro del territorio correspondiente a

31. El Proyecto Fitekantropus contempla la transformación del barrio La Balanza en Comas -sede de FITECA- a través de actividades lúdicas y culturales. El proyecto al que se hace mención es la transformación del comedor popular en Centro Comunitario gracias al financiamiento de la Universidad Politécnica de Madrid, el Foro Nacional Internacional, la Universidad de Alicante, el Ayuntamiento de Eibar, el Ayuntamiento de Errenteria (Rentería), la Generalitat Valenciana y la Municipalidad de Comas; y a la participación de colectivos de arquitectos, artistas y vecinos de la zona. El proyecto obtiene el segundo lugar en el Cuarto Concurso Internacional de Proyectos de Desarrollo Urbano e Inclusión Social CAF 2015. 


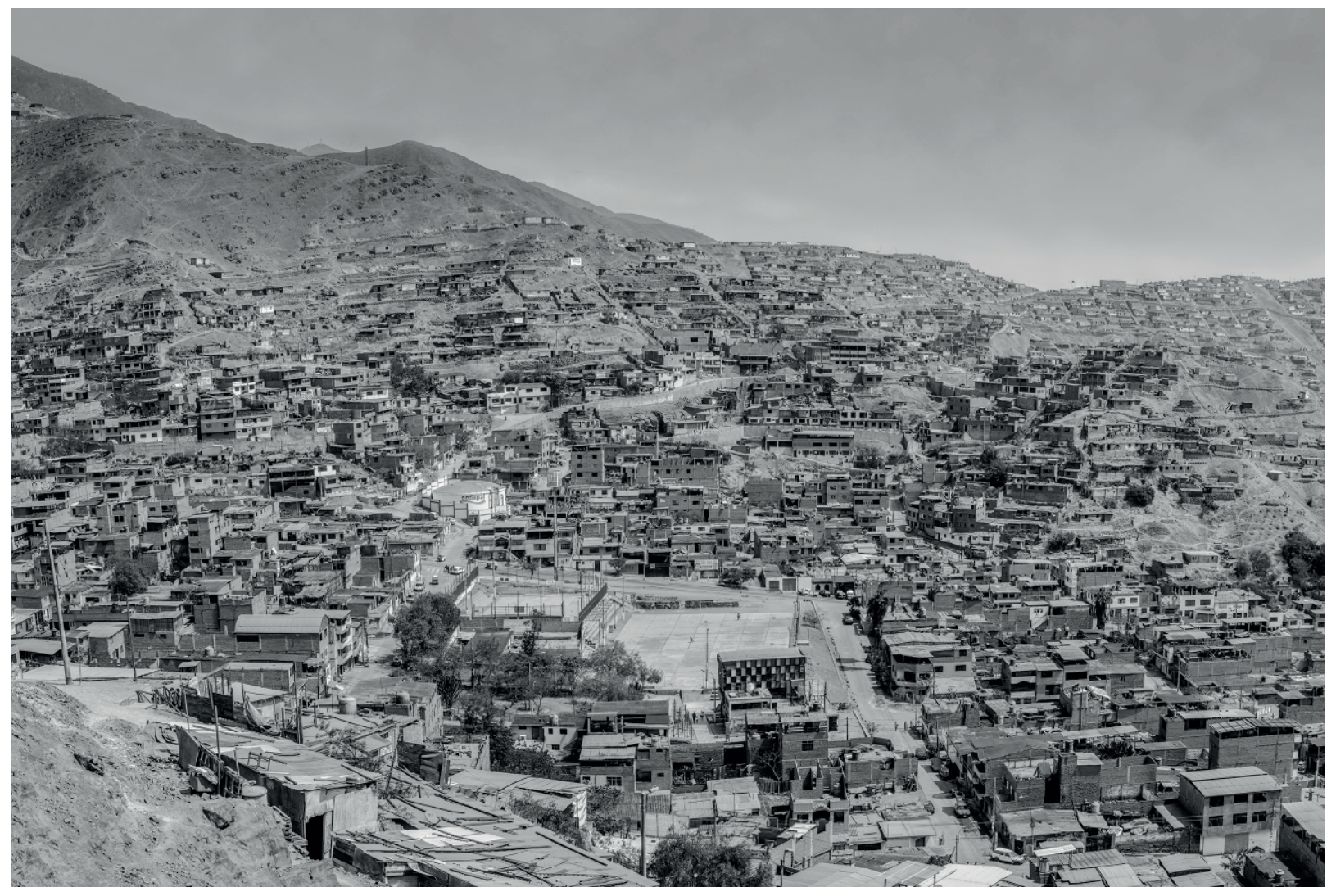

Lima, se simplifican las ideas en los binomios de centroperiferia o de oasis-desierto. La alta cultura ha buscado la negación del desierto como realidad tangible para utilizar únicamente su idealización y continuar con la construcción del oasis.

Sin embargo, los ejemplos revisados nos pueden dar algunas luces sobre cómo entender este territorio como posibilidad de creación de un espacio común, teniendo delante la inminente desertificación del territorio. De los proyectos de Baracco, por ejemplo, podemos rescatar el valor de la construcción artesanal tradicional como un medio de consolidación de un espacio que se urbaniza rápidamente. Con el estudio Barclay \& Crousse se pone en evidencia la validez de un espacio intermedio que sirve de interlocutor entre el paisaje y la arquitectura, que renuncia a su monumentalidad para privilegiar las relaciones entre el ser humano y el entorno. Finalmente, el Proyecto Fitekantropus, así como una serie de intervenciones anónimas que no forman parte de la historiografía de la arquitectura contemporánea y que se proponen como discusión pendiente, abordan el problema del desierto desde la pluralidad cultural, la condición participativa y las dinámicas cambiantes de una ciudad que está aún en construcción.

Podemos concluir diciendo que la invención del desierto es una construcción abierta y constante que, probablemente, seguirá en transformación. La indagación sobre el espacio y el paisaje debe tomar en cuenta los ideales que presenta una utopía que puede operar como modelo en la medida que la realidad se afianza cada vez 
más cuando busca acercarse a ella. Su especulación abstracta constituye el espejo sobre el cual se reflejan los ideales de una cultura que está tratando de definirse. Como construcción abierta, su importancia radica en su posibilidad de futuro, a la cual la arquitectura contemporánea debe prestar especial atención, sobre todo porque el desierto ha dejado de ser hace muchos años un territorio inhóspito y periférico y, más bien, se ha convertido en el centro de desarrollo de la cultura y sociedad de un país que, cada vez con mayor intensidad, se aleja del oasis para adentrarse en el desierto.

Aportación de cada autor:

Octavio Montestruque Bisso (OMB): Conceptualización, curación de los datos, y edición del documento final. Desarrollo de la investigación, diseño de la metodología y redacción del artículo.

Richard Asto Altamirano (RAA): Búsqueda bibliográfica, selección y edición de las imágenes y gestión de los permisos para su publicación. Desarrollo de la investigación y diseño de la metodología.

Autoría: OMB y RAA (50\% - 50\%) 


\section{Bibliografía citada}

BARACCO, Juvenal. Espacio sin límites. Lima: Art Lautrec, 1990.

CACCIATORE, Francesco; FOTI, Fabrizio. Barclay \& Crousse. Segnali di vita tra i due deserti. Siracusa: LetteraVentidue, 2012.

CASTILLO, Juan Manuel del. Lima la fértil: la inconsistencia del discurso de la ciudad-desierto. En: La Chimenea. Revista de arquitectura [en línea]. 1412-2014 [consulta: 08-01-2021]. Disponible en: http://revistalachimenea.blogspot.com/2014/12/lima-la-fertil.html?utm_medium=website\&utm_ source=archdaily.pe.

CAVAGNARO, Franco. Más allá de la estética: Jorge Eduardo Eielson frente al legado prehispánico. En: Devenir, enero-junio 2017, n. ${ }^{\circ}$ 7, pp. 101-116. ISSN: $2312-7562$.

CLÉMENT, Gilles. Jardins, paysage et génie naturel. París: Collège de France, 2012.

COGORNO, Gilda; ORTIZ DE ZEVALLOS, Pilar. La Lima que encontró Pizarro. Lima: Taurus, 2018.

CORNER, James. Recovering Landscape. Essays in Contemporary Landscape Architecture. Nueva York: Princeton Architectural Press, 1999.

CROUSSE, Jean Pierre. El paisaje peruano. Landscape in Central Andes. Lima: Pontificia Universidad Católica del Perú, 2021. CRUZ, Alberto; IOMMI, Godofredo. Ciudad abierta: de la utopía al espejismo. En: Revista Universitaria, 1983, n. ${ }^{\circ}$, pp. 17-25.

LÓPEZ, Miguel, ed. Rafael Hastingss. El futuro es nuestro y/o por un pasado mejor 1983-1967. Lima: ICPNA, 2004.

LUDEÑA, Wiley. Con-cierto de-sierto barroco. En: ARQ, julio 2004, n. ${ }^{\circ}$ 57, pp. 10-13.

MATTA, Raúl. "Asia” (Lima, Perú), barrios cerrados para vacaciones de lujo. En: L'Ordinaire des Amériques [en línea]. 2007 publicado el 6 de diciembre de 2016, n. 207 [consulta: 07-02-2021]. Disponible en: http://journals.openedition.org/orda/3366; DOl: https://doi.org/10.4000/orda.3366.

MINISTERIO DEL AMBIENTE. La desertificación en el Perú. Cuarta Comunicación Nacional del Perú a la Convención de Lucha contra la Desertificación y la Sequía. Lima: Fondo Editorial del MINAM, 2011.

PADILLA, José Ignacio, ed. Nu/do. Homenaje a Jorge Eduardo Eielson. Lima: Pontificia Universidad Católica del Perú, 2002.

PROTZEL, Javier. Continuidades, hibridaciones y rupturas. En: América Latina Hoy, 2001, n. 28, pp. 149-169. ISSN: 1130-2887.

RAMíREZ NIETO, Jorge. Las huellas que revela el tiempo (1985-2011). Seminarios de Arquitectura Latinoamericana (SAL). Bogotá: Universidad Nacional de Colombia, 2013.

REBAZA SORALUZ, Luis. De ultramodernidades y sus contemporáneos. Lima: Fondo de Cultura Económica, 2017.

SALAZAR BONDY, Sebastián. El desierto habita en la ciudad. En: Guaraguao, 2004, n. 18 , pp. 169-175.

Octavio Montestruque Bisso (Lima, 1984) Ph.D. en Composición Arquitectónica por la Università IUAV di Venezia, M.Sc. en Arquitectura: historia, teoría y crítica por la Universidad Nacional de Ingeniería y Arquitecto por la Universidad Ricardo Palma. Profesor asociado en la Universidad de Lima en las áreas de Proyectos e Historia y teoría de la arquitectura. Autor del libro "Juvenal Baracco. La memoria de la ciudad, las formas de la tradición" editado por la Universidad Ricardo Palma y coordinador del libro, investigación y exposición "Mario Bianco. El espacio moderno en el Perú", editado por la Universidad de Lima. Socio del estudio ANDES con sede en Lima, Perú.

Richard Asto Altamirano (Lima, 1989) Magíster en Arquitectura del Paisaje por la Pontifica Universidad Católica de Chile y arquitecto por la Universidad San Pedro de Chimbote. Docente en la UPC y UCAL en las áreas de Proyectos, Paisaje y Representación Arquitectónica. Socio fundador del estudio ANDES con sede en Lima, Perú. 
LA INVENCIÓN DEL DESIERTO. ARTE Y ARQUITECTURA DESDE LA COSTA PERUANA INVENTION OF THE DESERT. ART AND ARCHITECTURE FROM THE PERUVIAN COAST

Octavio Montestruque Bisso (https://orcid.org/0000-0002-6211-4789)

Richard Asto Altamirano (https://orcid.org/0000-0003-4332-2977)

\section{p.17 ALL IS NOT DESERT}

To talk about landscape is complex because the concept itself and its perception changes over time with society and culture. Its construction is the product of the interaction between human beings and the natural environment, where coexistence gives rise to civilizations and generates their developments. As several contemporary authors explain, "the landscape is intimately linked to the perception of the human being about the environment. This perception is not exempt from an aesthetic charge"1.

The transformation of the environment to ensure such coexistence turns the landscape into an artifice. It is a project, an invention that incorporates the ideas and perceptions of a human group at a given historical moment. We can make the distinction between landscape and environment, stating that the first "is what we keep in memory after having stopped looking", while the second concept "tries to give an objective reading of what surrounds us"2. The complexity of its management lies in the understanding of its relationships and in its reading as a reflection of human thought, in the adaptation of nature to its world view and to its survival needs.

Although the narrative of the desert has been addressed by Lima architecture in recent decades, this text proposes a reading of the landscape as a reference for art and architecture, which interprets it as something idealized and static. However, there is also the desert as a reflection of the urban reality overflowed several decades ago in the Peruvian capital city, and it is presented as a changing, peripheral and precarious space. The future habitability of the desert as a common space happens precisely because its recognition as a landscape under construction, as something that "redefines the world not only by its physical and experiential characteristics, but also by its eidetic content, that is, its capacity to contain and express ideas"3.

p.18 If you think about the Peruvian landscape, the desert does not appear as an immediate reference ${ }^{4}$. The Peruvian desert is a narrow strip that stretches between the Pacific Ocean and the Andes Mountains as a continuation of the Atacama Desert. This desert strip is interrupted by various landscapes such as wetlands, dry forests and valleys. Lima is founded in one of them, the Rimac Valley, which now extends through the Chillon Valley, to the north, and the Lurin Valley to the south.

When Pizarro arrived in the Americas, he decided to establish the administrative center of the continent in Lima, not only for the possibility of connecting with Europe by sea, but also because it was a fertile, densely populated place, and had a nice climate and roads that allow the exploration of the territory in all directions.

For this reason, the Peruvian capital city has been considered, for many years, a garden city. The chroniclers of the colonization present this territory as a heterogeneous space. In fact, "the soil of Lima is $18 \%$ sandy, $29 \%$ valley and $53 \%$ mountain range (rock)"6. The idea of the garden city is an ideological construction of the Lima elite of the nineteenth century ${ }^{7}$, which imagines a territory similar to the one that the Europeans found upon their arrival in the lands of the Americas. Despite this, the narrative of the desert appears constantly in art and architecture as an idyllic setting since the second half of the twentieth century. The desert becomes an invention that is far from the real conformation of the territory, but that gives us some signs about the current process of desertification ${ }^{8}$, a worrying factor, and not romantic as they wanted to conceive (figures 1 and 2).

\section{IN AND OUT}

At the beginning of the twentieth century, the modernizing process boosted the growth of the capital city. Since 1940, the population has grown drastically, from 645,000 to around 5 million only four decades later ${ }^{9}$. During this period, the city expanded by urbanizing agricultural areas, occupying arid areas and destroying the irrigation systems of the valley built by the ancient Peruvians, for whom "the nearest desert was not (...) a dominant and romantic imaginary that should be kept barren, but transformed into life. Not the barren desert, but the voluptuous abundance of the valley and its hills. The 'oasis' of the Peruvian architectural elites as a universe and not as an exception"10 (figure 3).

The separation and inequity in the settlement of the territory establishes a center-outskirts relationship, a constant in the spatial organization that has had strong repercussions in the way of perceiving us as part of a collective. The society and cities are conceived from the dichotomy of the idealized center and the dystopia being built in the desert outskirts, in many cases as urban settlements. Towards the end of the twentieth century, the desert became an important portion of the urban reality and is considered as part of the landscape of the city (figures 4 and 5).

One of the first critical readings of the center-outskirts relationship as a reflection of the oasis-desert dichotomy was made by the writer Sebastian Salazar Bondy, in the book Lima la horrible (Horrible Lima) from 1964. The essay seeks

p.21 a vindicating position of the indigenous -the desert, the outskirts- over the colonial -the oasis, the center- through a critical reading of the city. The desert appears as a social and cultural reality, as a mental construction that has characteristics that go beyond its arid nature that is away from the center.

Salazar Bondy articulates his narrative from the confrontation with the material reality -called landscape and architecture-, as well as with the immaterial reality, that is, society and its ways of life ${ }^{11}$, which appears when the city 
expands and crosses the barriers of the oasis towards the desert. The denial of the desert is presented as a nostalgic condition of the oasis when the separation between the center and the outskirts begins to break. Although by the end of the twentieth century almost two thirds of the metropolitan area were built in the hills and arid areas, the desert landscape is idealized as a peripheral space that denotes a return to the origins of the civilizations of the Peruvian coast and allows conceptual speculation in art and architecture.

In the second half of the twentieth century, some artists seek a connection between the desert and the past, in a p.22 peripheral and idealized landscape. It is not a marginal space, but takes on phenomenological connotations that leave a mark on the depths of the artistic sensibility. The desert becomes an invention, in the sense that it contrasts with the European aspects that would have prevailed in the colonial city and therefore, has the possibility of including the narrative of a modernity founded on nationalist ideas. The desert is not presented as a tangible reality, but as a mental construct that allows to think, in abstract terms, about the roots in one's own. "In Peru, the third phase of modernity starts with two trends, one that organizes the duality [colonialism-nationalism], both vertical and progressive linear (...), and another that, relying on the importance that nationalism gives the native, proposes a horizontal fusion that does not put the notion of progress aside. The first trend presents the indigenous -the outskirts- as humanly incapable of forming another metropolis (...). The second trend raises the possibility that in the indigenous lies a modernizing energy that has to survive a non-European mentality that is progressively diluted in an ideal process of miscegenation"12.

\section{THE IDEALIZATION OF A LANDSCAPE}

In contrast to what can happen in a logical system, the invention of the desert is a utopian condition that has value as long as it does not take place ${ }^{13}$, a frozen and infinite space that serves as a laboratory for what is being built in reality. The memory is a tool that allows filtering and classifying the relevant aspects from the own perception of the environment; it also has the potential to reconstruct the past from the affective connections that may happen in the present, just as Jorge Eduardo Eielson, a Peruvian artist who at the age of twenty-four migrated to Europe in 1948, did. For Eielson, the memory of the desert is the only link he maintains with Peru and, therefore, the thread that connects it with an autochthonous identity. His work is based on concepts such as the traces of movement, the frozen time, the feeling of emptiness and the condition of ruin ${ }^{14}$, ideas that are articulated thanks to his childhood memories on the beaches of Lima.

In the open work Paisaje infinito de la costa peruana (Infinite landscape of the Peruvian coast), the artist explores the desert as a territory currently not occupied, but that has vestiges of the presence of the human being due to the remains that he has left. The same desert sand that is carried to Europe ${ }^{15}$ appears in his material paintings; on it, drawn words, bones and feathers of birds or pieces of fabric show that nature becomes landscape -and therefore, space appears -through an almost archaeological work that reveals life in a place where its existence is apparently impossible ${ }^{16}$.

Emilio Rodriguez Larrain, who researches the delimitation of space in order to give a human scale to the immeasurable landscape, created La maquina de arcilla (The clay machine) in 1987, which is an intervention on the north coast that uses adobe walls to delimit enclosed spaces, some of them unreachable, and intermediate spaces that enable a connection between the person and the landscape. He introduces the idea of dual space, one that is both indoors and outdoors at the same time. This is the first key to a better understanding of this landscape, which consists of a series of defined and suggested spaces that react to the conditions of nature through their materiality, degrading due to weather and abandonment, gradually turning into a modern ruin eroded by the infinite and timeless desert ${ }^{17}$ (figure 6). p.23 Another element that shapes the invention of this landscape is that it was envisioned as a mystical place. In 1980, the artist Rafael Hastings, in collaboration with the architect Juvenal Baracco, reflected on it with a conceptual proposal called A twelve journey plot about levitation. Hastings describes the intervention as a theatrical action that takes place in the desert, about 300 kilometers to the south of Lima. He features a twelve-week journey through which the main character moves on the borderline between fiction and reality to finally levitate out of this world. According to Hastings, "since the arrival of the Spaniards to America, this is the first time that the landscape has been treated (...) through the symbolic action of man as part of it (...); the landscape has always been portrayed as an isolated entity, as nature (...). As a result, space is different and faces the poorly repertorized [sic] weather of the current urban settlement in Latin America, which is increasingly reliant on the industrial time. In this work, the adjustment to time is an adjustment to the desert, to the divine"18 (figure 7).

The proposal is presented with a poster that includes a series of vignettes that describe the scenes imagined by Hastings and the structures designed by Baracco. It also includes a map with thirty scenes located in the territory and that connect the human beings to nature. The desert gained mystical value in the moment when human beings face it and try to inhabit it. The reading of the landscape suggests a return to the origins, a vital relationship between man 
and the emptiness on which the oldest cultures of Peru are based ${ }^{19}$, announcing an interest in understanding and theorizing about the space built in the Peruvian desert.

\section{INHABITING THE DESERT}

The return to the origins of the field also means a return to the origins of one's own culture. For example, Juvenal Baracco, in his workshop at the Ricardo Palma University, states as a working hypothesis that "it is possible to conceive all the universal architectural problems within the framework of the space corresponding to the Peruvian territory and society. (...). Only then will architecture be a permanent cultural value"20.

In the 1980s, some works with these characteristics appeared as a strategy to address the habitability of the desert. Peruvian architects speculated on the possibility of modernity in an original architecture, especially in the one located on the Peruvian coast. The architecture was presented as an abstract mass that outlines voids within the landscape, where the modern language is nourished by ancient art and architecture. In this case, artists and referents are temporarily distant, but they belong to the same territory.

p.24 The Ghezzi house, designed in 1984 by Juvenal Baracco, is one of the most notable examples of intervention in the desert. This is the first contemporary architectural work that theorizes about the relationship between a man and his landscape, and at the time, it was widely publicized as an example of resistance against the "uncomfortable feeling of permanent reliance. The reliance on images applied to modify the rigorous and bare lines that characterized the modern movement" ${ }^{21}$. In the Ghezzi house, Baracco addresses the relationship with the arid landscape of the desert. He takes references from austere architecture of pre-Hispanic origins, as well as from informal occupations in the urban outskirts. The result is a construction that uses two opposing forms: a solid U-shaped volume and a rustic wooden structure. The volume houses the spaces of traditional housing and articulates a space that, delimited by the wooden structure, is directly related to the landscape. This project seeks to inhabit the inhospitable desert by enveloping the voids that are generated in it (figures 8 and 9).

The Ghezzi house was not conceived as an isolated work. The architect creates a set of houses that explore the occupation of the desert by replicating the characteristics of the space that is defined in an austere way, with simple

p.25 elements and handcrafted construction. This space of mediation between architecture and landscape is repeated and adapted as a whole, building a residential development model that meets the conditions of the environment. Unfortunately, as we will see later, this system of settlement is not going to be copied in future beach residential developments, which rather deny the desert and seek to reproduce the urban characteristics of the oasis. The value of Baracco's proposal lies in the understanding of the landscape as a cultural construction, which was a reflection of the self-built outskirts of Lima during the years in which he projected the complex (figure 10).

In the mid-1980s, after the years of military government and with the rise of terrorism in the country, there was an increase in the settlement of land on the Lima city outskirts. This was due to squatter settlements ${ }^{22}$ as a result of

p.27 internal migrations, and to gated residential developments for people who seek to get away from the city. While the first situation was a result of poverty and marginality, the latter was formalized through the creation of gated and exclusive residential developments. Towards the end of the twentieth century, the desert revealed itself in two simultaneous situations: as a dystopia for thousands of citizens without access to basic necessities such as housing, and as a utopian weekend scenario for a wealthy class of Lima society ${ }^{23}$.

The development of the real estate market encouraged the rapid settlement of the beachfront areas in the south of the city, reproducing the oasis condition that Lima presented in the 19th century and which is compared with the North American model of gated community ${ }^{24}$. This created a scenario that responds by denying the desert, both in its social and natural dimensions. This phenomenon transferred the urban housing typology to the outskirts without being able to articulate a narrative with the landscape as it had been done for some years in art and architecture. The main characteristic of these urban settlements is the artificiality used to create open and cohabitation spaces, whether through membership clubs, golf courses or artificial lagoons. In other words, the real landscape serves only as a backdrop for the creation of an idyllic scenography. The desire for homogenization within these residential developments, governed by severe building and behavioral regulations ${ }^{25}$, seeks to create an inner world that represents a denial of the real desert and its outdoors (figure 11).

Since the 2000s, Peruvian architecture has mainly focused on designing weekend houses for the Lima elite. It is recurrent to use the narrative of the desert without referring to the currents of thought of the contemporary landscape, but rather as a strategy to justify the compositional freedom of the architect. Mistakenly, the desert turns out into a

p.28 lack of context and references, which leads to a formalist architecture that follows some late modern trends. With few exceptions, the architecture proposed in these places seeks to reproduce an anonymous urban setting, stripped from the plastic, spatial, temporal and mystical possibilities that have resulted from the invention of the desert, relying only to an apparent formal minimalism and generic plastered walls finishes.

The first houses built by the Barclay \& Crousse studio ${ }^{26}$ at La Escondida beach, located 100 kilometers south of Lima, represent a change. In this residential development, there are fewer building restrictions, which allows architects to include the color and exposed materials. However, the most outstanding feature found in these houses is the denial of a rigid division between indoors and outdoors, creating intermediate spaces where the landscape can be inhabited. To this end, "on the one hand, the layout keeps the perimeter enclosure; on the other hand, the layout is completely reversed: the location of the rooms is centripetal with respect to the location of the voids, which are centrifugal"27, also 
expressing an interest in the void of the open spaces that "represents an extension to the exterior of the main spaces of the house"28 (figure 12).

In reference to the landscape, Crousse states that "the modern western vision of reality has emphasized on the being and the object, while the eastern and Andean visions privilege the evolution and the connection"29; this argument could also be applied to interpret the architecture of the studio. In it, the space of connection between the parts is more important, a type of space that is open, but built within the limits of the architecture, as Rodriguez Larrain or Baracco do. In these intermediate spaces, the connection with the landscape is verified and the desert is inhabited (figure 13). The interventions that face the desert as an urban reality are less common. In this case, the desert suggests outdoors, plurality, lack of resources and richness of interactions, which are conditions opposed to the idea of oasis on which the colonial city is conceived.

The desert also suggests cultural diversity due to migrations. As a result, self-managed and self-built neighborhoods have emerged, which in many cases are consolidated as administrative areas after some decades. A good example of this is Comas, located in the northern part of Lima. The multiculturalism and the tradition of collaborative and community work in this administrative area have led to the organization of many groups in the La Balanza neighborhood, where the Festival Internacional de Teatro en Calles Abiertas - FITECA (Street theater Festival) has been held since 2001, with great local impact and the participation of hundreds of artists.

Since 2007, the group CITIO Ciudad Transdisciplinar ${ }^{30}$ (Transdisciplinary City), which later became the CCC-Coordinadora de la Ciudad en Construccion (Coordinating Committee of the City under Construction)-, has developed a cultural space project on the outskirts of the city. The Fitekantropus Project is created ${ }^{31}$ working with the simplicity and synthesis of a self-construction process and the typical strengths of community organization of Peruvian culture prior to colonial times. The work provides a space where a group of people interact in a playful way with their environment, understanding the diversity as a possibility of progress and modernity. The close relationship between landscape, architecture and society makes Fitekantropus an open and growing project by its users. This interpretation of the context as changing and heterogeneous urban reality provides new values to the invention of the desert as a utopia that materializes slowly in the city: it allows us to open up the possibilities of a contemporary architecture that can be participatory, austere and capable of generating effective changes in the lives of citizens who live in the outskirts, and not only for those who are able to have access to the oasis (figures 14 and 15).

\section{THE FUTURE OF THE DESERT}

After a brief overview of the interests aroused by the desert in Peruvian art and architecture during the second half of the twentieth century, the first thing we can confirm is the strong centralism of Lima. Over the last few decades, architects from the capital city have mistakenly created the narrative of the desert as an instrument for the standardization of Peruvian architecture. Even within the territory belonging to Lima, ideas are simplified in the binomials of centeroutskirts or oasis-desert. High culture has sought the denial of the desert as a tangible reality to use only its idealization and continue with the construction of the oasis.

However, the examples reviewed may shed some light on how to understand this territory as a possibility for the creation of a common space, given the imminent desertification of the territory. For example, from Baracco's projects, we can point out the value of traditional handcrafted construction as a means of consolidating a fast, developing urban space. The work of Barclay \& Crousse studio highlights the validity of an intermediate space that serves as an agent between the landscape and architecture, which waives its monumentality to privilege the relationship between the human being and the environment. Finally, the Fitekantropus Project, as well as a series of anonymous interventions that are not part of the historiography of contemporary architecture and that are suggested as pending discussion, addresses the problem of the desert from the perspective of the cultural plurality, the participatory condition and the changing dynamics of a city that is still under construction.

We can conclude by stating that the invention of the desert is an open and constant construction that will probably continue to be transformed. The exploration of space and landscape must consider the ideals presented by a utopia that can work as a model to the extent that reality becomes increasingly strong when it seeks to approach it. Its abstract speculation represents the mirror on which the ideals of a culture that is trying to define itself are reflected. As an open construction, its importance lies in its possibility for the future, to which the contemporary architecture must pay special attention, especially because the desert has long ceased to be an inhospitable and remote territory and, rather, has become the center of development of the culture and society of a country that, with increasing intensity, is moving away from the oasis to get into the desert.

Contribution of each author:

Octavio Montestruque Bisso (OMB): Concept development, data curation, and editing of the final document. Research development, methodology design and writing of the paper.

Richard Asto Altamirano (RAA): Bibliographic search, selection and editing of images, and arranging permissions for publication. Research development and methodology design.

Authorship: OMB and RAA (50\% - 50\%) 
1. CROUSSE, Jean Pierre. The Peruvian landscape. Landscape in Central Andes. Lima: Pontificia Universidad Catolica del Peru, 2021, p. 35.

2. CLEMENT, Gilles. Jardins, paysage et génie naturel. Paris: College de France, 2012, pp. 10-11.

3. CORNER, James. Recovering Landscape. Essays in Contemporary Landscape Architecture. New York: Princeton Architectural Press, 1999, p. 1.

4. Peru is surely imagined as an Andean territory, cradle of ancient civilizations. Analyzed from its extent, $60 \%$ of the territory is Amazon rainforest and, despite that, the Amazon is a forgotten space when talking about national identity.

5. COGORNO, Gilda; ORTIZ DE ZEVALLOS, Pilar. La Lima que encontró Pizarro. Lima: Taurus, 2018

6. CASTILLO, Juan Manuel del. Lima la fértil: la inconsistencia del discurso de la ciudad-desierto. In: La Chimenea. Revista de arquitectura [online]. December 14, 2014 [Retrieved January 8, 2021]. Available in: http://revistalachimenea.blogspot.com/2014/12/lima-la-fertil.html?utm_medium=website\&utm_source=archdaily.pe.

7. LUDEÑA, Wiley. Con-cierto de-sierto barroco. In: ARQ, July 2004, No. 57, pp. 10-13.

8. The process of desertification which the three valleys of Lima go through has been accentuated in recent years. The territory of Lima has been affected by urban expansion, whether planned or not. In both cases, the value of the land is prioritized as a building space and not as part of a territory that must be managed on a large scale. According to a report by the Ministry of the Environment, the human factors contributing to the process of desertification of the Peruvian coast are the "loss of agricultural soils around the cities, reduction of wetlands and overpopulation".

9. PROTZEL, Javier. Continuidades, hibridaciones y rupturas. In:America Latina Hoy, 2001, No. 28, pp. 149-169.

10. CASTILLO, Juan Manuel del, op. cit. supra, reference 6.

11. SALAZAR BONDY, Sebastian. El desierto habita en la ciudad. In: Guaraguao, 2004, No. 18, pp. 169-175.

12. REBAZA SORALUZ, Luis. De ultramodernidades y sus contemporáneos. Lima: Fondo de Cultura Económica, 2017, p. 28.

13. CRUZ, Alberto; IOMMI, Godofredo. Ciudad abierta: de la utopía al espejismo. In: Revista Universitaria, 1983, №. 9, pp. 17-25.

14. CAVAGNARO, Franco. Más allá de la estética: Jorge Eduardo Eielson frente al legado prehispánico. In: Devenir, January-June 2017, №. 7, pp. $101-116$.

15. PADILLA, Jose Ignacio, ed. Nu/do. Homenaje a Jorge Eduardo Eielson. Lima: Pontificia Universidad Catolica del Peru, 2002.

16. To delve into the artist's work, the catalog of the retrospective exhibition Eielson can be reviewed, organized by the Museo de Arte de Lima between November 16, 2017 and March 4, 2018. The painting Poema (Poem) from 1977, where the artist explores the ideas mentioned in this text, is interesting.

17. To delve into the artist's work, the catalog of the retrospective exhibition Rodriguez Larrain can be reviewed, organized by the Museo de Arte de Lima between March 16 and August 4, 2016. The works Refugio de los Andes (Refuge of the Andes) and La maquina de arcilla (The clay machine), from 1985 and 1987 respectively, where the artist explores the ideas mentioned in this text, are interesting.

18. LOPEZ, Miguel, ed. Rafael Hastings. El futuro es nuestro y/o por un pasado mejor 1983-1967. Lima: ICPNA, 2004, p. 223.

19. Idem.

20. BARACCO, Juvenal. Espacio sin límites. Lima: Art Lautrec, 1990, p. 8.

21. RAMIREZ NIETO, Jorge. Las huellas que revela el tiempo (1985-2011). Seminarios de Arquitectura Latinoamericana (SAL). Bogotá: Universidad Nacional de Colombia, 2013, pp. 77-78.

22. The settlement of the outskirts began in 1933 with the Leticia neighborhood on San Cristobal hill in the area of Rimac -part of the founding sector of the city-. These squatter settlements continue to this day, but a dramatic increase is detected in the 1980 s.

23. LUDEÑA, Wiley, op. cit. supra, reference 7.

24. MATTA, Raul. "Asia” (Lima, Peru), barrios cerrados para vacaciones de lujo. In: L'Ordinaire des Amériques [online], 2007 published on December 6th, 2016 , No. 207 [Retrieved February 07, 2021]. Retrieved from: http://journals.openedition.org/orda/3366; DOl: https://doi.org/10.4000/orda.3366.

25. Although there are some differences between the regulations of each residential development, a large number of them require the use of white plastered walls, the use of some exposed materials or the incorporation of colors is restricted and the height of each house is regulated according to its proximity to the sea. In addition, there are behavioral regulations regarding the domestic staff from each family, including the use of uniforms and restrictions on the use of the beach and access to the sea at certain times. In other words, an ancient social system linked to the colonial and aristocratic world, which was asleep in the city and awakens in these exclusive communities, is revealed.

26. Studio directed by Peruvian architects Sandra Barclay and Jean Pierre Crousse. It is important to mention that both have been outstanding students of Juvenal Baracco's workshop at the Ricardo Palma University, from where they graduated, he in 1987 and she in 1990. It was during this period that Baracco's vertical workshop placed special emphasis on the possibility of building a contemporary architecture with strong roots in Peruvian territory and society.

27. CACCIATORE, Francesco; FOTI, Fabrizio. Barclay \& Crousse. Segnali di vita tra i due deserti. Siracusa: LetteraVentidue, 2012, p. 13.

28. Idem.

29. CROUSSE, Jean Pierre, op. cit. supra, reference 1, p. 43.

30. The CITIO Ciudad Transdisciplinar (Transdisciplinary City) group is formed by a group of young Peruvian architects comitte to work in "emerging, vulnerable and conflictive areas of Lima, promoting culture, art, and creativity aimed at the appropriation of the public space while assuming a critical and proactive role in facing the challenges of sustainable human development and the problems of living" (CITIO Ciudad Transdisciplinar). Their presence has been fundamental in creating Festival Internacional de Teatro en Calles Abiertas (FITECA). The architects involved in the two stages of the project were: Stage 1: Javier Vera, Lucia Nogales, Eleazar Cuadros; Stage 2: Javier Vera, Eleazar Cuadros, Paula Villar, David Fontcuberta, Exequiel Collantes. In addition, several group, the municipal government, universities, and volunteer groups collaborate with this project. 31. The Fitekantropus Project aims to transform La Balanza neighborhood in Comas -headquarters of FITECA- through recreational and cultural activities. This project is the transformation of the soup kitchen into a Community Center thanks to funding from the Polytechnic University of Madrid, the International National Forum, the University of Alicante, the municipality of Eibar, the municipality of Errenteria (Renteria), the Generalitat Valenciana and the municipality of Comas, and the participation of the groups of architects, artists, and neighbors of the area. The project won the second place in the Fourth International Competition for Urban Development and Social Inclusion Projects CAF 2015. 


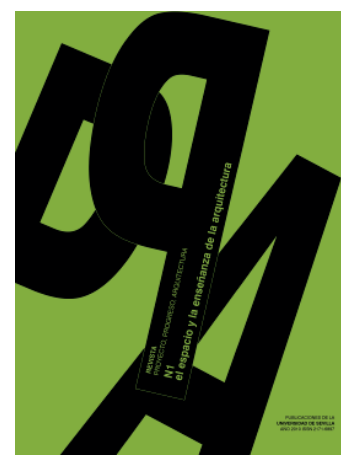

PpA N01

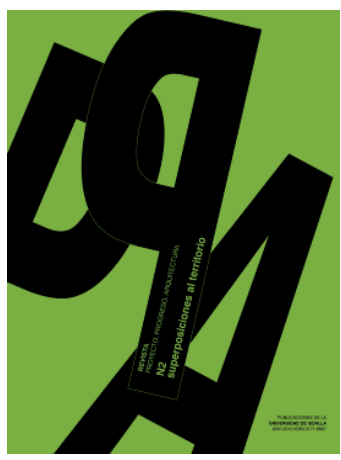

PpA N02

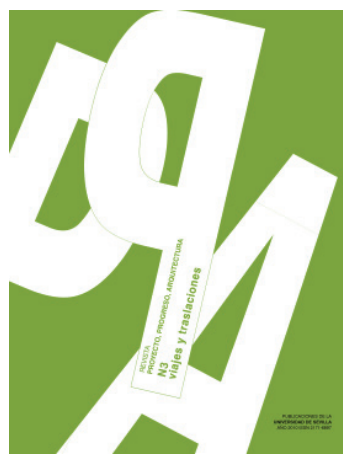

PpA N03

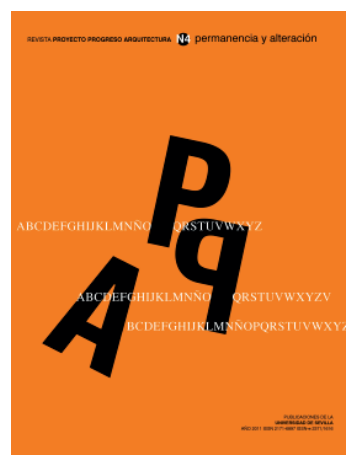

PpA N04

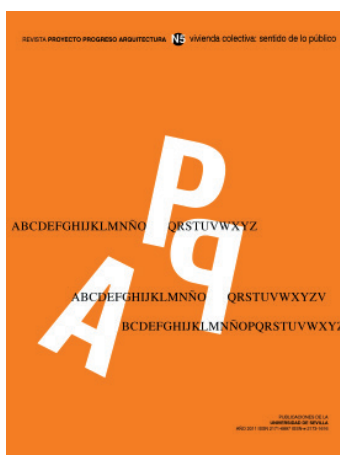

PPA N05

N01. EL ESPACIO Y LA ENSEÑANZA DE LA ARQUITECTURA (mayo, 2010) / N02. SUPERPOSICIONES AL TERRITORIO (mayo 2010) / N03. VIAJES Y TRASLACIONES (noviembre 2010) / N04. PERMANENCIA Y ALTERACIÓN (mayo 2011) / NO5. VIVIENDA COLECTIVA: SENTIDO DE LO PÚBLICO (noviembre 2011)

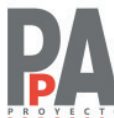

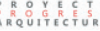

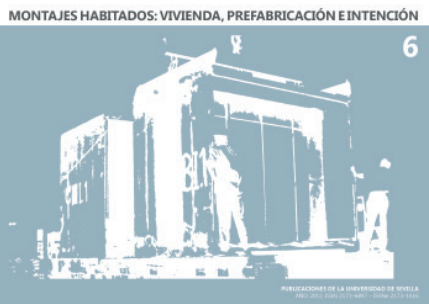

PpA N06

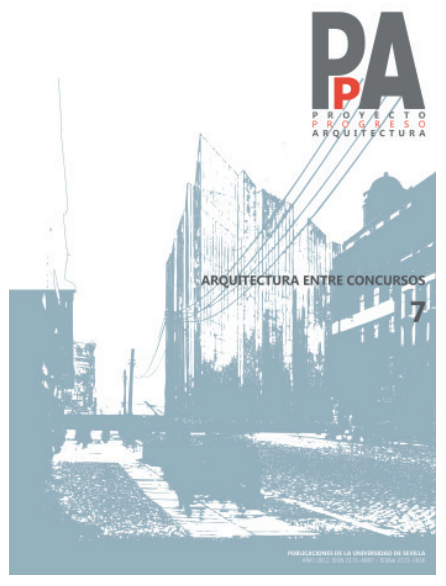

PpA N07

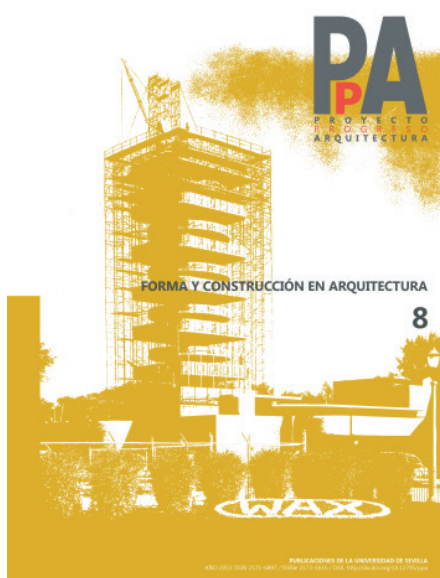

PpA N08

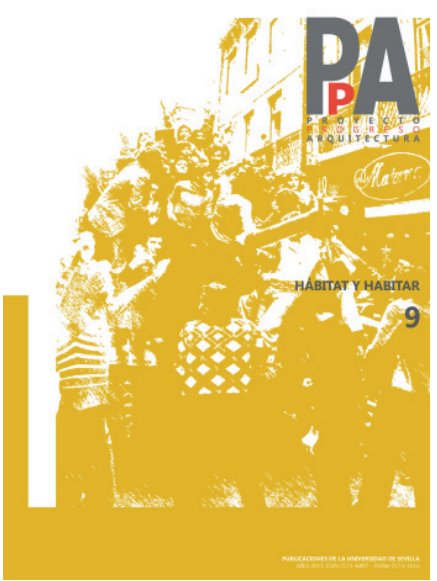

PpA N09

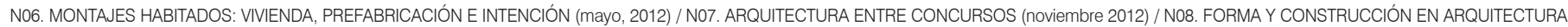
(mayo 2013) / N09. HÁBITAT Y HABITAR (noviembre 2013)

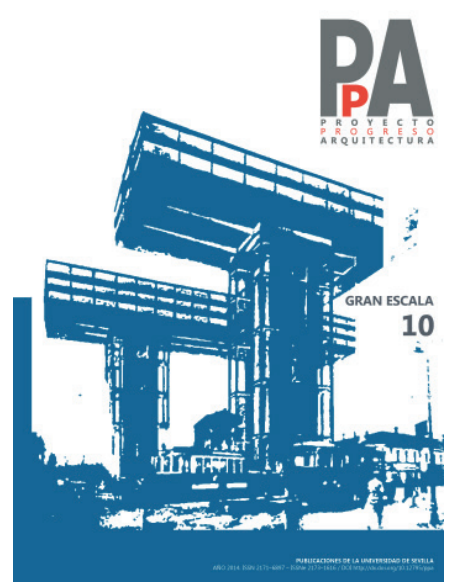

PpA N10

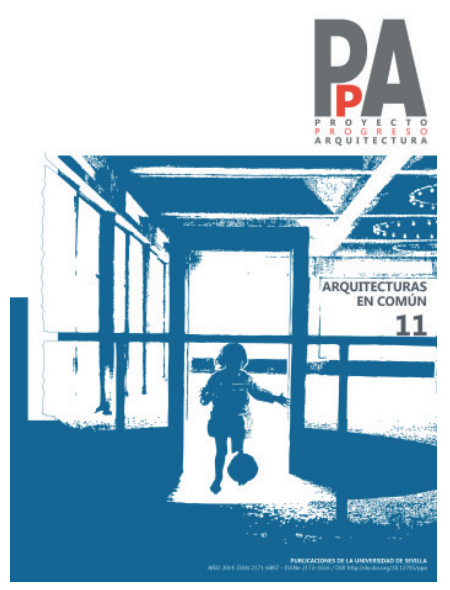

PpA N11

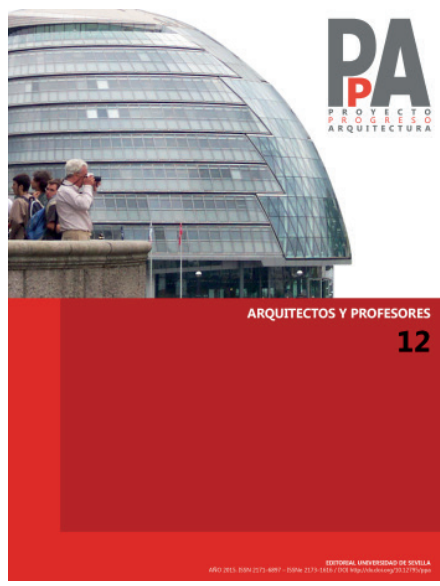

PpA N12

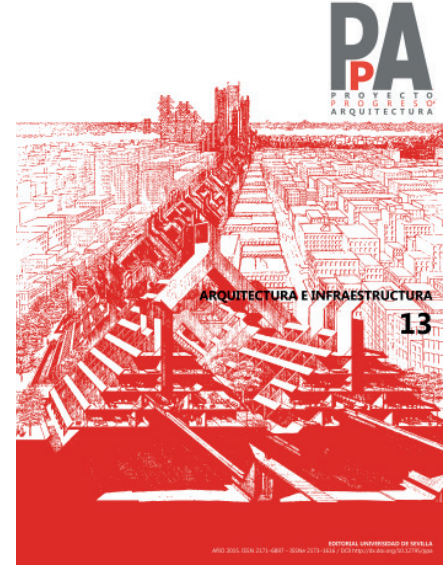

PpA N13

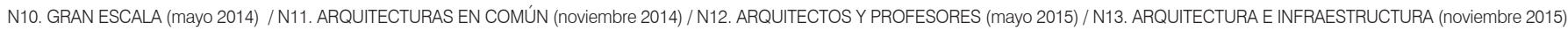




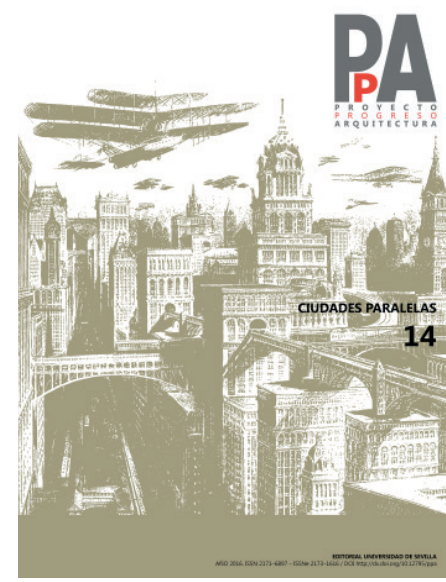

PpA N14

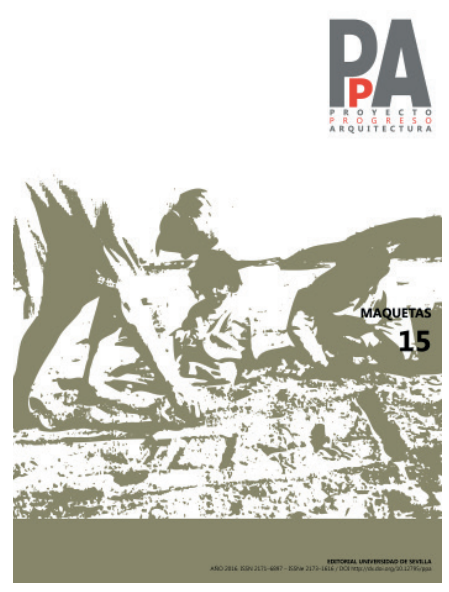

PpA N15
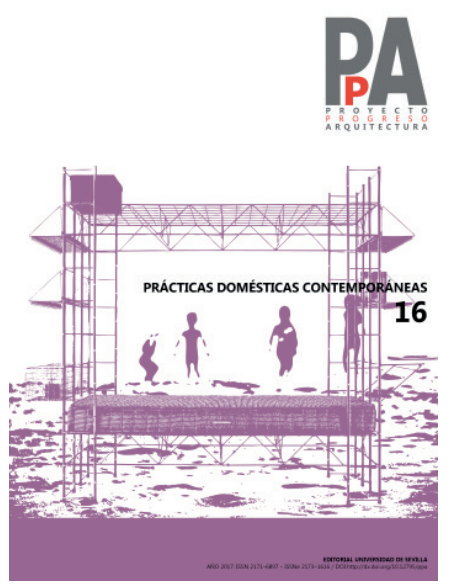

PpA N16

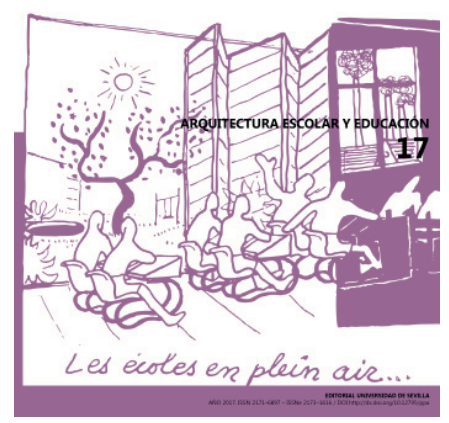

PPA N17

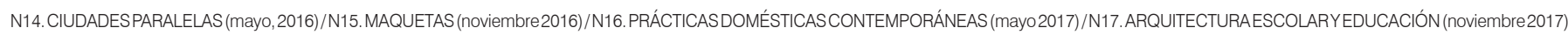

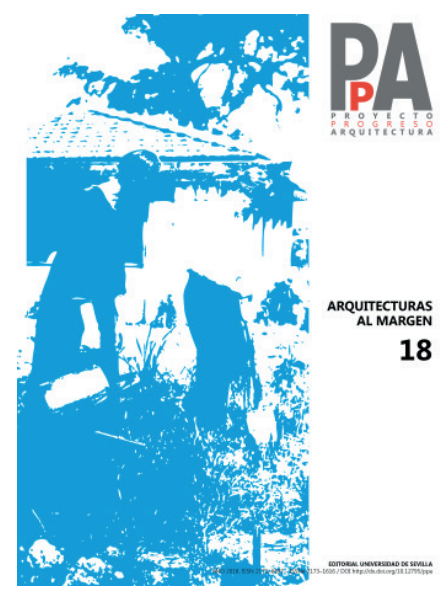

PpA N18

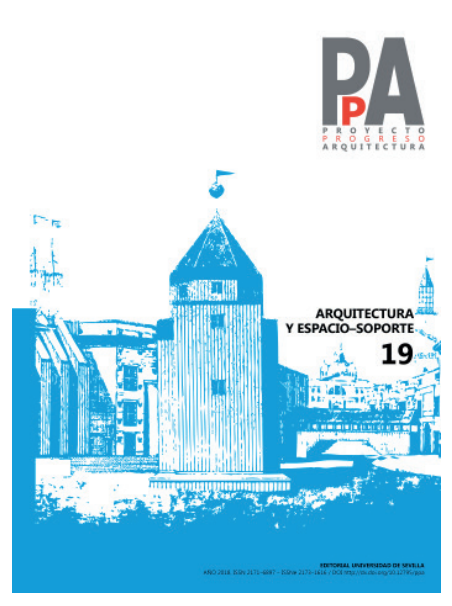

PpA N19

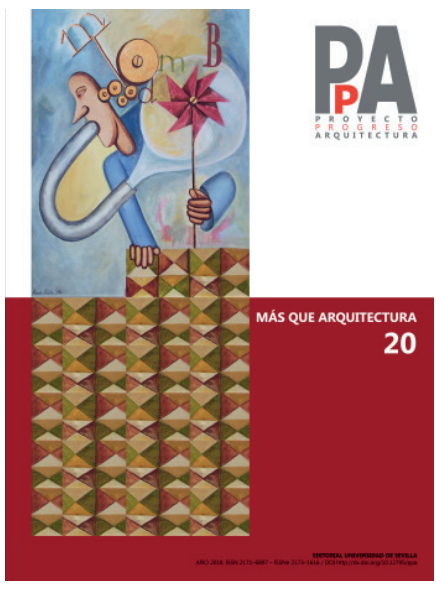

PpA N20

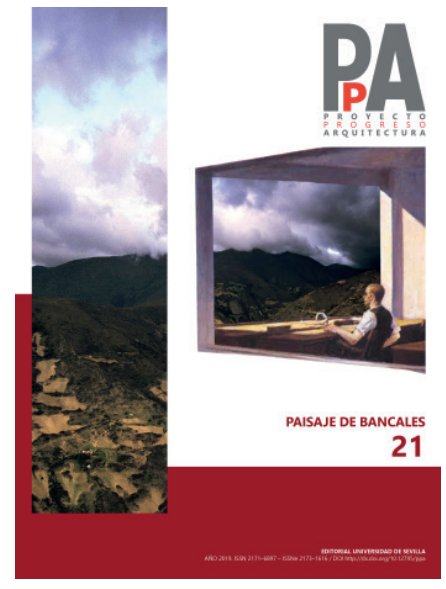

PpA N21

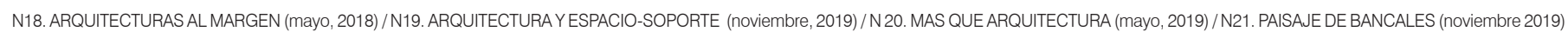

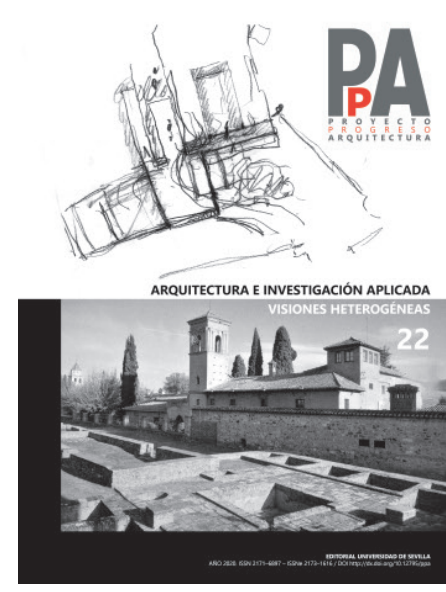

PpA N22

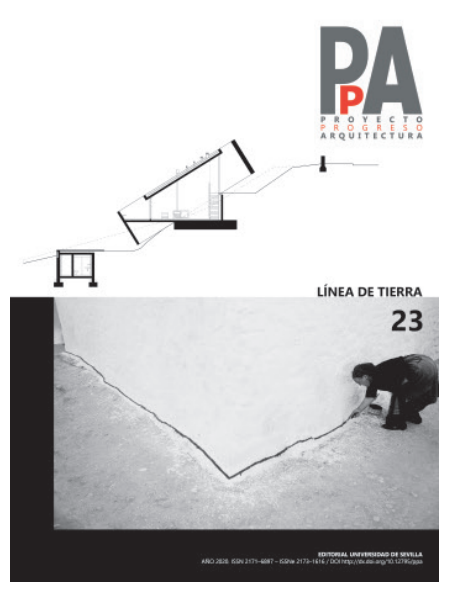

PpA N23
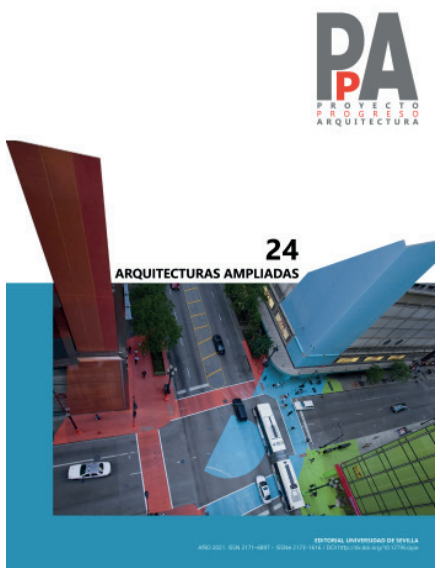

PpA N24

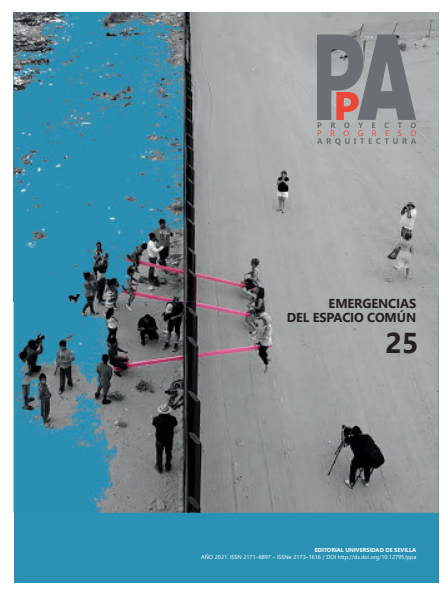

PpA N25

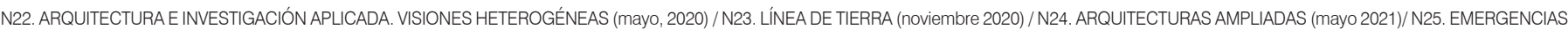
DEL ESPACIO COMÚN (noviembre 2021) 


\section{Autor imagen y fuente bibliográfica de procedencia}

Información facilitada por los autores de los artículos:

página 19, 1. Elaboración propia; página 19, 2. Elaboración propia; página 20, 3. Elaboración propia sobre la base de las fotografías satelitales del Servicio Aerofotográfico Nacional; página 21, 4. Servicio Aerofotográfico Nacional; página 21, 5. Servicio Aerofotográfico Nacional; página 23, 6: Sucesión Emilio Rodríguez Larraín; página $24,7$. Archivo privado Arquitecto Juvenal Baracco; página 25, 8. Archivo privado Arquitecto Juvenal Baracco; página 25, 9. Archivo privado Arquitecto Juvenal Baracco; página 26, 10. Archivo privado Arquitecto Juvenal Baracco; página 27, 11. Elaboración propia; página 28, 12. Fotografía de Jean Pierre Crousse. Archivo Barclay \& Crousse; página 29 , 13. Dibujo de Jean Pierre Crousse. Archivo Barclay \& Crousse; página 30, 14. Fotografía de Eleazar Cuadros. Archivo CCC; página 31, 15. Fotografía de Eleazar Cuadros. Archivo CCC; página 37, 1. The La Guardia and Wagner Archives, La Guardia Community College/The City University of New York; página 38, 2. Cortesía M. Paul Friedberg and Partners. Architectural Record, julio 1966, p. 197; página 39, 3. Cortesía M. Paul Friedberg and Partners. The Architectural Forum, julio-agosto 1966, p. 70; página 41, 4. Elaboración propia; página 42, 5. ๑ David Hirsch. Process: Architecture, 82, p. 31; página 43, 6. @ David Hirsch. Process: Architecture, 82, p. 32; página 43, 7. Cortesía M. Paul Friedberg and Partners. @ David Hirsch; página 44, 8. @ David Hirsch. Process: Architecture, 82, p. 32; página 45, 9. Cortesía M. Paul Friedberg and Partners. ๑ David Hirsch; página 46, 10. ๑ David Hirsch. Process: Architecture, 82, p. 33; página 46, 11. @ David Hirsch. Parks Council Records/Avery Architectural and Fine Arts Library, Columbia University. MOGILEVICH, Mariana. The invention of public space. Minneapolis: University of Minnesota Press, 2020, p. 36; página 46, 12. Cortesía M. Paul Friedberg and Partners. @ David Hirsch; página 47, 13. MOGILEVICH, Mariana. The invention of public space. Minneapolis: University of Minnesota Press, 2020, p. 37; página 48, 14. @ David Hirsch. Process: Architecture, 82, p. 30; página 52, 1. Elaboración propia, composición a partir de fotografías de Îñigo de Barron (izquierda y centro) y Nicolas Vigier (derecha), 2021; página 52, 2. Nicolas Vigier, 2021; página 53, 3. Erich Andres, sin fecha. Ministerio de Educación Cultura y Deporte, Centro Documental de la Memoria Histórica (ES.37274.CDMH//FOTOGRAFíAS-ERICH-ANDRES, 970 y ES.37274.CDMH//FOTOGRAFÍAS-ERICH-ANDRES, 972); página 54, 4. HURTWO0D, Marjory. Why Not Use Our Bomb Sites Like This? En: Picture Post, noviembre 1946, vol. 33, n. ${ }^{16}$, pp. 26-27; página 55, 5. Luis Bartolomé Marcos (LBM1948), 2021. Fotografía publicada en Wikimedia Commons bajo licencia Creative Commons Attribution-ShareAlike 4.0 International: https://creativecommons.org/licenses/by-sa/4.0/deed.en; página 57, 6. Elaboración propia, collage a partir de imágenes intervenidas procedentes de los Amsterdam City Archives, 2020; página 58, 7. Elaboración propia, collage a partir de imágenes procedentes de medios internacionales y redes sociales, 2021; página 59 y 60, Figuras 8 y 9 . Elaboración propia, 2015; página 62, 10: Records of Lady Allen of Hurtwood, Modern Records Centre, University of Warwick (MSS.121-AP-12-17-13). @ Feature Photography: Rosemary Mathews and Howell Evans; página 63, 11. John Drysdale, sin fecha. Records of Lady Allen of Hurtwood, Modern Records Centre, University of Warwick (MSS.121-AP-12-15-3). ๑ Camera Press (Text and Illustrations), London; página 63, 12. John Drysdale, sin fecha. Records of Lady Allen of Hurtwood, Modern Records Centre, University of Warwick (MSS.121-AP-12-15-2). @ Camera Press (Text and Illustrations), London; página 63, 13. Records of Lady Allen of Hurtwood, Modern Records Centre, University of Warwick (MSS.121-AP-12-1-20). @ Associated Press Photo from London; página 65, 14. Cortesía y @ Rael San Fratello, 2019; página 65, 15. RISSELADA, Max; HEUVEL, Dirk van den. Team 10, 1953-1981: In Search of a Utopia of the Present. Rotterdam: NAI Publishers, 2005, pp. 56-57; página 70, 1. Elaboración propia. Imágenes extraídas de Wikipedia (hoja 5/12 del plano de Nolli) y de Venturi, Robert; Scott-Brown, Denise; Izenour, Steven. Learning from Las Vegas. Cambridge: MIT Press, 1977; página 72, 2. Archivo Municipal del Ayuntamiento de Málagá. página 73, 3. Elaboración propia; página 74, 4. Archivo Municipal del Ayuntamiento de Málaga; página 74, 5. Archivo Municipal del Ayuntamiento de Málaga; página 75, 6. Archivo Histórico Provincial de Málaga. Delegación Provincial de Cultura. Signatura 14140/35. Fotografía Leiva; página 77, 7. Elaboración propia; página 78, 8. Elaboración propia; página 79, 9. MORALES FOLGUERA, José Miguel. La Alcazaba de Málaga en el s. xix. Entre la utopía y la realidad. En: Cuadernos de Arte de la Universidad de Granada [en línea]. Granada: Universidad de Granada, noviembre 1984, p. 441. Disponible en: https://revistaseug.ugr.es/index.php/caug/article/view/11109; página 80, 10. Foto Arenas; página 80, 11. Foto Arenas; página 80, 12. Archivo Histórico Fotográfico del Instituto de Estudios Fotográficos de Cataluña (IEFC). Fondo Thomas; página 81, 13. Foto Arenas; página 82, 14. Elaboración propia; página 83, 15. Elaboración propia; página 87, 1. Disponible en https://commons.wikimedia.org/wiki/ File:Untitled_(Xe_Biennale_de_Lyon)_(4103279111).jpg This file is licensed under the Creative Commons Attribution 2.0 Generic license; página 91, 2. Disponible en: https://www.leparisien.fr/seine-saint-denis-93/montreuil-sur-les-traces-de-georges-melies-08-06-2018-7761399.php; página 92, 3. Disponible en: https://www.cairn. info/revue-espaces-et-societes-2011-1-page-15.htm; página 93, 4 y 5. Planos extraídos del texto Les “boutiques" des artisans villageois dans la France d'Ancien Régime (XVle-début du XIXe siècle), escrito por Alain Belmont. En: Annales de Bretagne et des pays de l'Ouest. T. 106, n. ${ }^{\circ}$ 1, 1999.; página 94, 6 y 7. Grabados y dibujos extraídos de VIOLLET-LE-DUC, Eugène. Dictionnaire raisonné de l'architecture française du Xle au XVle siècle/Maison. París: Bance-Morel, ed., 1854-1868. T. 6. La Maison; página 96, 8y 9. ๑ Lacaton \& Vassal, Disponible en: https://www.lacatonvassal.com/index.php?idp=25; página 97, 10 y 11. Disponible en: https://www.inexhibit.com/case-studies/ infinite-places-the-french-pavilion-venice-architecture-biennale-2018/. @ Inexhibit; http://encoreheureux.org/category/news/?lang=en.; página 98, 12. @ La Machinerie. Extraída de VELEZ, Véronique; DEMERY, Cécile; MERCURIO, Céline Di. Etude prospective: Nouveaux usages et modes d'habiter [en línea]. París: L'Union Sociale pour I'Habitat, 2020 [consulta: 07-10-2021]. Disponible en: https://www.union-habitat.org/centre-de-ressources/patrimoine-maitrise-d-ouvrage/nouveaux-usages-et-modesd-habiter-analyse-d; página 99, 13. La Bricothèque; página 99, 14. @ Mon atelier en Ville. Extraídas de VELEZ, Véronique; DEMERY, Cécile; MERCURIO, Céline Di. Etude prospective: Nouveaux usages et modes d'habiter [en línea]. París: L'Union Sociale pour l'Habitat, 2020 [consulta: 07-10-2021]. Disponible en: https://www.union-habitat. org/centre-de-ressources/patrimoine-maitrise-d-ouvrage/nouveaux-usages-et-modes-d-habiter-analyse-d. 

PLAYGROUNDS AND COMMON SPACE. ON PLAYING IN THE SUSPENDED CITY. José Parra-Martínez; Nicolás Stutzin-Donoso; Juan Manuel López-Carreño • LA CALLE COMO ESCENOGRAFÍA URBANA. LAS TRANSFORMACIONES DE LARIOS Y ALCAZABILLA EN EL SIGLO XX / THE STREET AS URBAN SCENOGRAPHY. THE TRANSFORMATIONS OF CALLE LARIOS AND CALLE ALCAZABILLA IN THE TWENTIETH CENTURY. Luisa Alarcón González; Francisco Javier Montero-Fernández • EL BRICOLAJE AL TALLER O EL ESPACIO DE LA TRANSFORMACIÓN EN FRANCIA / FROM DO-IT-YOURSELF TO THE WORKSHOP, OR THE TRANSFORMATION SPACE IN FRANCE. Ophelia Mantz •

- IÑAKI ÁBALOS: PALACIOS COMUNALES ATEMPORALES. GENEALOGÍA Y ANATOMÍA . Daniel Díez Martínez • LE CORBUSIER: ¿CAÑONES, MUNICIONES? ¡GRACIAS! VIVIENDAS... POR FAVOR / JORGE TORRES CUECO Y JUAN CALATRAVA: UNA EXPOSICIÓN, UN PABELLÓN Y UN LIBRO: LE CORBUSIER, $1937-1938$ Ricardo Sánchez Lampreave • VICTORIANO SAINZ GUTIÉRREZ: ALDO ROSSI Y SEVILLA. EL SIGNIFICADO DE UNOS VIAJES. José Ignacio Linazasoro Rodríguez.
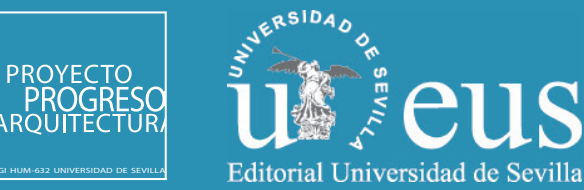